\title{
Social Screens and Systematic Boycott Risk
}

\author{
Hao (Arthur) Luo \\ DeGroote School of Business \\ McMaster University \\ luoha@mcmaster.ca
}

\author{
Ronald J. Balvers \\ DeGroote School of Business \\ McMaster University \\ balvers@mcmaster.ca
}

December 2014

\begin{abstract}
We consider the pricing implications of screens imposed by Socially Responsible Investing funds. The model extends standard risk-based asset pricing models by deriving as an additional systematic risk factor a portfolio of stocks shunned by a subgroup of institutional investors. We reconcile the empirically observed risk-adjusted sin-stock abnormal return with a "boycott risk premium" which has a substantial financial impact that is, however, not limited to the targeted firms. The boycott effect cannot readily be explained by litigation risk, a neglect effect, or liquidity considerations. The boycott factor is extremely useful in explaining cross-sectional differences in mean returns across industries.
\end{abstract}

\section{JEL Classification: G12.}

Keywords: $\quad$ Social Screens; Sin Stocks; Investment Boycotts; Systematic Risk

* The authors thank Andrew Carrothers, John Maheu, Clarence Kwan, Jiaping Qiu, Jimmy Ran, Kevin Veenstra and workshop participants at the Geneva Summit on Sustainable Finance, the EUROFIDAI $12^{\text {th }}$ International Paris Finance Meeting, McMaster University, and Lingnan University for helpful comments. 


\section{Introduction}

This paper evaluates the extent to which average expected stock return differences across industries may be attributed to a "boycott" risk premium. We derive a testable two-factor asset pricing model based on the assumption that morally guided investors are self-restricted from investing in controversial stocks. Formally the model is akin to the segmented investor base frameworks of Errunza and Losq (1985) and Merton (1987), and empirically we are motivated by the frequently observed abnormal sin-stock returns (e.g., Fabozzi, Ma and Oliphant, 2008; Hong and Kacperczyk, 2009; Statman and Glushkov, 2009; Salaber, 2009).

The boycott factor is derived as a systematic risk factor supplementing the conventional market factor. The additional risk dimension arises from the non-pecuniary preferences of a group of investors regarding a group of boycotted assets. "Arbitrage" by traditional investors who are exclusively interested in the pecuniary aspects calls for these investors to overweight boycotted assets in their portfolios, which requires a larger risk premium. The model explains the commonly observed sin stock return premium as resulting from the systematic boycott risk premium. The degree of "mispricing" is captured by a stock's sensitivity to the boycott risk factor. The pricing errors of any stocks, not only sin stocks, may be reduced by the systematic boycott risk factor: the boycott of particular stocks extends to other stocks whose returns happen to be positively correlated with boycotted stocks; for instance, stocks that employ similar inputs, or substitute stocks that are purchased by morally constrained investors in place of sin stocks.

The model shows that the boycott risk premium is always positive, with the magnitude of the premium determined by the financial capital represented in the group of morally constrained investors. Empirically, we compare the boycott risk premium through time, across periods during 
which norm-constrained institutions enhance the impact of moral constraints, and periods in which boycotting is mostly a private statement.

Following the prescriptions of Lewellen, Nagel, and Shanken (2010) in using the two-stage cross-sectional regression method, our boycott-augmented CAPM model dominates alternative models such as the CAPM, the Fama-French three-factor model (FF3), and the Carhart fourfactor model (FF4). We find robust pricing of a boycott risk premium across different industrybased test assets. The boycott risk premium is always quite similar across test assets.

Our paper supplements the existing literature on the financial impact of boycotts in two directions. First, we study the financial impact of extensive industry-wide boycotts as opposed to the individual-event-driven boycotts examined by Teoh, Welch, and Wazzan (1999). Second, besides explaining the superior performance of the so-called sin stocks relative to regular stocks, our model allows us to clarify the financial impact of boycotts on all stocks, including non-sin stocks. This externality of boycotts on other market participants is a result of the partial segmentation incorporated in the model.

\section{Some Stylized Facts Concerning Boycotted Industries}

Most boycotted industries fall into the category of "sin" industries. Depending on the definition of sin and the cultural or legal context of these sin industries, research reveals the following common features of sin firms.

\section{Risk-Adjusted Boycotted-Stock Returns}

Most studies on the topic of sin stocks focus on sin-stock or Vice-Fund performance relative to other traditional benchmarks. Utilizing sin-firm data from 1970 to 2007, Fabozzi, Ma and Oliphant (2008) (FMO hereafter) show that on average a portfolio of sin stocks produces an 
annual return of 19.02 percent, while the average market return is only 7.87 percent annualized. ${ }^{1}$ Hong and Kacperczyk (2009) (HK hereafter), using time series regressions for the sample period 1965-2006, hold a portfolio of sin stocks and sell short a portfolio of non-sin stocks. This strategy produces abnormal returns of 26 basis points per month. In a cross-sectional regression, after accounting for market size, past return and market-to-book ratio, they find that sin stocks outperform comparable stocks by 29 basis points per month. Statman and Glushkov (2009) construct a reverse sin portfolio, "accepted minus shunned", revised annually over the period 1991-2007. They find that this portfolio has a negative 2.6 percent annualized excess return by the Fama-French three-factor benchmarks; and a negative 3.3 percent annualized excess return by the CAPM benchmark. Other anecdotal evidence regarding positive abnormal returns for sin stocks includes Lemieux (2003), Ahrens (2004), and Waxler (2004).

The consensus on the superior sin-stock performance inspired a stream of studies about the determinants of the sin premium. Salaber (2007) explores the sin premium of European stocks from a legal and a religious perspective. She shows that Protestants require higher risk-adjusted returns on sin stocks than do Catholics. She further finds that sin stocks have higher risk-adjusted returns if these sin stocks are in an environment subject to higher litigation risks and excise taxation. Salaber (2009) studies sin-stock returns over the business cycle. She finds an indication of higher risk in that an abnormal number of these stocks exit during recessions. Durand, Koh, and Tan (2013) link sin stock performance world-wide to cultural variables. They find that when cultures become more individualistic, sin stocks tend to outperform other stocks. FMO propose possible arguments for the sin stocks' abnormal returns. They speculate that sin industries are typically less competitive and are more subject to litigation and headline risks. These risks lead

\footnotetext{
${ }^{1}$ Their annual sin stock return is numerically very close to the boycott premium implied from our model, even though our set of boycotted stocks differs substantially from the set FMO uses.
} 
to a permanent discount in valuation. They further attribute the positive risk-adjusted returns to initial IPO undervaluation resulting from the nature of the business of these firms.

\section{Norm-Constrained Institutions Hold Fewer Boycotted Stocks}

HK (2009) represent another stream of empirical research that ties the undervaluation of sin stocks to the lack of investor base. Their work is motivated by Merton's (1987) work on neglected stocks and segmented markets. Merton (1987) explicitly derives a linear relationship between a stock's expected return and its shadow cost resulting from incomplete information. HK show that due to the increasingly popular social screens, sin stocks have lower levels of institutional ownership. The reduced popularity of sin stocks dampens analyst coverage of these sin stocks further. Less coverage of sin stocks decreases awareness of these stocks which increases the sin-stock risk premium based on Merton's neglect effect. Sin firms seem to be aware of at least the asymmetric information component of this negative neglect effect on their market value. Kim and Venkatachalam (2011) show that financial reporting quality of sin firms is superior relative to their control groups. Leventis, Hasan, and Dedoulis (2013) find moreover that sin firms are willing to pay higher fees to have their financial statements audited.

\section{Selection Process of Boycotted Firms}

Boycotted industries are typically controversial industries and are difficult to categorize objectively. Therefore, we base our selection procedure on previous studies as well as on surveys from real practices in the investment industry (in particular, the US Social Investment Forum, SIF, 1995-2012 biannual surveys).

Socially Responsible Investing (SRI) as an investment category was implemented on a significant scale starting in the mid-1990s. See Table 1. According to the Social Investment 
Forum (SIF) 2012, more than one of every nine dollars under professional management in the US is now invested according to SRI guidelines. Over $90 \%$ of the funds following SRI guidelines use three or more screens to constrain their investments in controversial businesses. The top five screens based on the SIF biannual surveys between 1995 and 2005 were tobacco, alcohol, gaming, weapons, and environment. While the first three are lumped together as "sin" industries (see, for example, Salabar 2007; FOM 2008; HK 2009), the screen on environment is fueled by concerns of global warming and fossil fuel divestment. ${ }^{2}$

To identify a representative portfolio of boycotted stocks we follow a two-pronged approach by selecting (1) a minimal list of habitually boycotted stocks, and (2) a more extensive list of less universally boycotted stocks. The first has the advantage of excluding stocks that are not uniformly boycotted by most SRI funds over the period considered, while the second provides a broader, more diversified portfolio. The top five industries that are screened most frequently by SRI funds are alcohol, fossil fuel, gaming, weapons, and tobacco. Each is screened by around 80 percent or a higher fraction of the SRI funds (see Table 3). We take a value-weighted portfolio of all CRSP firms in these industries as our more extensive boycott factor portfolio.

Several components of the extensive set of boycotted firms are questionable as reliable indicators of a boycott. First, including the gaming industry is problematic. Since the late 1990s, an increasing number of states in the US has deregulated casino style gambling. According to a survey of casino entertainment by the National Gaming Association, by 2013, 23 states had legalized casino-style gambling. The wave of legalization of casino-style gaming suggests that

\footnotetext{
${ }^{2}$ The primary goal of fossil fuel divestment is to pressure government and fossil fuel industries (oil, gas, coal) to undergo "transformative change" with the objective of causing a drastic reduction in carbon emissions. This divestment campaign has gained prominence on university campuses and mission driven institutions - a phenomenon that is quite similar to the history of divestment from South Africa in protest against South Africa's system of Apartheid.
} 
gaming has become more socially acceptable in recent years. This observation is enforced by the significant drop in the percentage of gaming screens used by the SRI portfolios, from its peak of $86 \%$ in 1999 to less than $20 \%$ in the beginning of 2003 . If sensitivity to a boycott factor depressed prices of gaming firms, a systematic reduction of this sensitivity would lead to an impact on returns spuriously attributed to the boycott factor. ${ }^{3}$

Second, including all fossil fuel firms is difficult. According to the "Stranded Assets Program," a report by Oxford University, commissioned by HSBC's Climate Change Centre of Excellence, oil and gas together account for about $10 \%, 11 \%$, and $20 \%$ of the total market cap of the Russell 1000, the S\&P 500, and the FTSE 100, respectively. In contrast, coal is a much smaller and more fragmented industry. The coal industry's size and its salient pollution make it a more likely scapegoat among the three fossil industries. For instance, the world's largest sovereign wealth fund, the Government Pension Fund of Norway, has divested itself from 13 coal extractors without similar actions toward oil and gas companies.

Third, we follow the literature in dropping weapons as a morally questionable industry, following Salabar (2007) and HK (2009). The resulting narrower list of boycotted firms consists of alcohol, coal, and tobacco firms. Table 2 provides systematic year-by-year summary statistics

\footnotetext{
${ }^{3}$ Additionally, including gaming firms is problematic for the earlier part of our sample due to a survivorship bias. As noted by Chari, Jagannathan, and Ofer (1986), stocks move in and out of the COMPUSTAT list depending on their performance. All gaming firms identified in previous studies are based on the COMPUSTAT Segment Current File. The Current File only covers stocks starting from 1985. HK (2009) back-fill firms in 1985 to 1926. This practice, while legitimate for their study creates survivorship bias for our full sample period regressions. Additionally, HK (2009)'s gaming firms are identified by the North American Industry Classification System (NAICS) which was not implemented until 1999. Therefore, gaming firms that did not survive through 1997 were not on the list. Moreover, firms that report data in the Segment File are typically large firms operating in multiple sectors. Including these firms will cause our value-weighted boycott factor to be strongly influenced by firms that only partially operate in boycotted industries. Consequently, the degree of "sinfulness" in our boycott factor is watered down. For example, Coco Cola would be on the list of boycotted firms based on the Segment File (as part of its operations involves alcohol), whereas it is also part of the FTSE KLD 400 social index.
} 
regarding the boycotted stocks beginning in 1963 and ending in 2012. Over the entire sample period, there are per year on average 33 boycotted stocks in our narrow boycott measure and 199 boycotted stocks in our broader boycott measure.

The selection of a limited number of clearly boycotted stocks is meant to deliver the best proxy for a more abstract larger portfolio of assets boycotted to different degrees with each asset's weight in the portfolio depending positively on its market weight as well as the degree to which it is boycotted. Thus, while the combined market value of the average of 33 boycotted stocks is negligible, it is used as a proxy for a portfolio with a total market value more similar to the total value of capital invested in institutions with social screens. Our narrow measure is conservative in the sense that only stocks are included that are pervasively and persistently shunned by socially responsible investors. We also consider a broader classification of boycotted stocks that includes around 200 firms on average.

\section{Derivation of Boycott Implications}

The position of boycotted stocks in the overall financial market is interesting. Boycotted firms still have access to the financial market but face reduced demand from a group of morally influenced investors. To attract a sufficient number of investors, boycotted firms must offer higher returns. We formally introduce this effect by segmenting the market into a group of unrestricted investors and a group of morally guided investors. We follow Merton (1987) with two crucial differences. First, instead of the investor inattention assumed by Merton, here morally guided investors are aware of all investment options but simply prefer not to own stocks of particular firms engaged in activities they find morally reprehensible. Second, instead of the diagonal covariance structure assumed by Merton, here stock returns have a general covariance 
structure which formally allows us to examine the importance of boycotting as a systematic risk variable. The resulting model is akin to that in Errunza and Losq (1985). ${ }^{4}$

\section{The Theoretical Model}

The effect of social screens is incorporated in the model by assuming that a fraction of investors is morally influenced. These investors refuse to invest in assets whose underlying activities they find morally unacceptable. An immediate implication is that two types of investors no longer have identical investment opportunities. Two types of investors with different investment opportunity sets generally choose two different optimal portfolios. This implies that the standard CAPM is no longer valid and that, in addition to the market factor, a second systematic risk factor emerges which we shall refer to as the "boycott" factor.

The formal model is presented in the Appendix. In the standard CAPM environment we introduce the existence of a group of investors who “...get direct utility from their holdings of some assets, above and beyond the utility from general consumption that the payoffs on the assets provide." (Fama and French, 2007, p.675). In our case this is disutility from holding sin stocks. Fama and French cite SRI as an example with specific reference to tobacco companies and gun manufacturers (p.675). Fama and French (2007) point out that the CAPM fails to hold in this setting but consider the case in which the direct tastes for assets are diffuse. One may also easily interpret Merton (1987) as applying to a case in which some assets are neglected by investors with distaste for the underlying activities that the assets represent. Here the model also represents a diffuse group of assets. As a result, while both Merton (1987) and Fama and French (2007) point out the implied failing of the CAPM, they do not identify a systematic way in which

\footnotetext{
${ }^{4}$ Errunza and Losq (1985) consider international market segmentation in which investors in one country are restricted from investing in the other country, but not the other way around. Key modeling differences with our model, however, are that they assume in effect constant absolute risk aversion, which is not necessary in our context. They further superimpose a factor structure on asset returns which also is not necessary in our case.
} 
the model fails. However, given our assumption that the direct distaste for assets follows a pattern and applies to a specific (non-negligible) market segment (group of assets and investors), it becomes possible to identify a systematic factor that not only describes but is sufficient for describing the way in which the CAPM fails to hold theoretically.

The derivation in the Appendix provides the two-factor result

$$
\mu_{i}=\beta_{i m} \mu_{m}+\beta_{i b} \mu_{b}
$$

In which the mean excess return of any asset $i$ is determined by the asset's sensitivity to the market risk factor $\beta_{i m}$ as well as by its sensitivity to a "boycott" factor $\beta_{i b}$. The boycott factor is the return on the portfolio of all sin stocks hedged to remove the correlation of sin stock returns with the remainder of the market. Thus the boycott factor represents the risk characteristics of the part of the sin portfolio that is a distinct addition to the market, representing the risk diversification opportunities lacking for the restricted investors.

The intuition for the two risk factors is to capture the preferences of two distinct groups of investors (morally constrained and unrestricted). Theoretically, the (different) tangency portfolios for the representative investors of these two groups suffice as the risk factors. However, these portfolios are not observable. The unrestricted investors, for instance, do not simply hold the market portfolio but in equilibrium hold all of the sin stocks while reducing their holdings of non-sin stocks that have returns positively correlated with the sin stocks that are over-weighted in their portfolios relative to the market portfolio. The market portfolio and the boycott portfolio together represent the tangency portfolios of both investor types: the restricted investors hold the market portfolio and short the boycott portfolio (such that their net holdings of 
sin stocks is zero) while the tangency portfolio of the unrestricted investors consists of positive holdings of the market and the boycott portfolio. See Figure 1.

In market equilibrium, a holder of either the market portfolio or the boycott portfolio removes risk from the market and receives a systematic risk premium in return. Any asset is accordingly priced by how much risk it contributes to each of the two portfolios $\left(\beta_{i m}, \beta_{i b}\right)$ and by how much the market values the risk of each $\left(\mu_{m}, \mu_{b}\right)$. One may take risks unrelated to these two portfolios, but as it does not remove risk from the market this risk is not priced and does not affect mean returns.

The interpretation of the risk factors as representing underlying real macroeconomic risks is not identified in the model. This is most easily understood by superimposing a factor structure on the thus-far general mean-variance structure of the returns and assuming a large number of assets exists with finite idiosyncratic risk. If we had a one factor model with, say, unanticipated production growth as the sole factor shock then the risk content of both the market factor and the boycott factor would be reducible to this production risk only, and could be summarized by the loadings on the one risk factor. On the other hand, if there were a K-factor model consisting of $\mathrm{K}>2$ underlying real shocks, the market factor and boycott factor would become distinct linear combinations of the $\mathrm{K}$ shocks. Although the $\mathrm{K}$ real factor values then cannot be fully identified from the market and boycott portfolio returns, the two portfolios are nevertheless sufficient to capture the risk that is priced in the market. The upshot is that, in our model, it is possible that the two factors represent recognizable macroeconomic risks, but in a world with a variety of macroeconomic state variables the relation between risk factors and underlying macro risk may be complex. 
Our theoretical results differ significantly from those in Merton (1987). The Merton framework has been used previously to explain the sin premium. For instance by HK. The neglect of stocks that investors are uninformed about is analogous and formally identical in the model to neglect of stocks that investors are morally disinclined to purchase. Nevertheless the implication from the Merton model is different from ours: sin stocks have idiosyncratic abnormal returns rather than a special systematic risk premium. There are two reasons for this difference. First, the Merton model is a one-factor model in which idiosyncratic risk is priced. The idiosyncratic risk being priced stems from an assumption of insufficient assets for full diversification and it would matter even if there were no neglect (either because there is no incomplete information problem or because no investors have moral compunctions). The presence of neglect merely reinforces the impact of the idiosyncratic risk: if, say, half the investors neglect to buy a stock then in equilibrium this stock's supply is split over half as many investors, doubling the idiosyncratic risk and the related return premium (Merton 1987, eq. 16). Thus the abnormal return is proportionate to the degree of neglect as well as the quantity of idiosyncratic risk. However, the return premium disappears as the number of existing assets increases and would be quantitatively very small in a realistic setting with many risky assets.

Second, Merton does not examine the systematic impact of commonalities in the neglect of assets. This is reasonable under the incomplete information interpretation since acquiring information is costly for basically any asset. If neglect is due to moral distaste, however, it is easier to identify a group of assets avoided by a group of investors which allows us to look at the systematic pricing effects without invoking idiosyncratic risk.

While it is difficult to justify a large return premium for sin stocks in the Merton perspective with idiosyncratic risk premia, the return premium for sin stocks in our framework due to 
systematic risk may well be large. It hinges on the economic importance of the group of morally constrained investors relative to the value of the portfolio of boycotted stocks (see equation 14). In addition to the fact that more than $11 \%$ of investment under management formally applies moral investment constraints, an unknown fraction of private investors is guided at least in part by such tastes. "Arbitrage" by unrestricted investors does not eliminate the return premium, but it does require a large enough group of restricted investors. See Pontiff and maybe Petajisto.

\section{Implications and Intuition}

From equation (8), the solution for the relative price vector of the risky assets is solved in terms of underlying variables as:

$$
\mathbf{p}=\overline{\mathbf{x}}-\left(\gamma \Sigma \overline{\mathbf{n}}+\delta \Sigma \overline{\mathbf{n}}_{\mathbf{B}}\right),
$$

pre-multiplying by a vector of holdings of portfolio $i$ yields for a specific asset or portfolio $i$ that $p_{i}=\overline{\mathbf{n}}_{\mathbf{i}}^{\prime} \mathbf{p}=x_{i}-\gamma \Sigma_{i m}-\delta \Sigma_{i b}$. The existence of morally guided investors of type 2 means that $q_{2}>$ 0 . It follows that $\delta>0$ (defined below equation 8), meaning that the price of boycott risk is positive: the larger an asset or portfolio $i$ 's payoff covariance, $\Sigma_{i b} \equiv \overline{\mathbf{n}}_{\mathbf{i}}^{\prime} \Sigma \overline{\mathbf{n}}_{\mathbf{B}}$, with the boycott factor payoff, the lower its price relative to the risk free asset, $p_{i}=P_{i} / P_{f}=P_{i}\left(1+R_{f}\right)$, and the higher its expected excess return, $\mu_{i}=\left(\overline{\mathbf{n}}_{\mathbf{i}}^{\prime} \overline{\mathbf{x}} / P_{i}\right)-\left(1 / P_{f}\right)$.

The intuition is that reduced demand from the morally guided investors lowers the price of the boycotted stock which makes it more attractive for "arbitrage" by unrestricted investors. As the unrestricted investors accumulate boycotted stocks in addition to their market holdings, the supplementary risk, to the extent that it is unrelated to the market, starts to carry an additional 
risk premium in equilibrium necessary to entice the unrestricted investors to purchase the surplus of boycotted stocks. Variation in this boycott risk premium across assets depends on $\Sigma_{i b}$, the basic covariance in payoffs between the asset and the boycott factor. It is not whether or not the asset is boycotted by the moral investors that determines the premium, but how much the asset's payoff covaries with the boycott factor.

Thus, the existence of type 2 investors lowers the prices of assets that are correlated with the boycott factor. If the goal of SRI is to increase the cost of capital of socially questionable businesses and consequently discourage their influence, equation (13) suggests that this goal is achievable. To the extent that the correlated assets are sin assets the boycott accomplishes the desirable objective of the moral investors to lower values of objectionable businesses, reducing the incentive to expand these businesses. Alternatively put, the lower prices for given payoff distribution raise the expected returns and thus the cost of equity of these assets, reducing investment in related activities. Note of course that, since the quantity of existing projects $\overline{\mathbf{n}}$ is fixed in the model, only the price effects of the demand effect due to boycotts can be derived formally.

However, the same price effects will apply to assets that have no sin content but happen to have payoffs that are correlated with the boycott factor. For instance, a sin firm and a non-sin firm may use the same inputs. If the boycott factor is also influenced by these input prices, the boycott will have the effect of discouraging investment in the activities of both the sin stock and the non-sin stock. For this reason, boycotting sin stocks is an effective but somewhat blunt instrument for discouraging morally or socially objectionable activity. 
To consider more specifically the comparative statics impact of boycotting by the moral investors, assume that the degrees of absolute risk aversion are similar for both groups of investors: $\theta=\theta_{1}=\theta_{2}{ }^{5}$ With a constant number of investors, an increase in the size of the group of moral investors means $d q_{2}=-d q_{1}>0$. Given $\theta_{1}=\theta_{2}$ the increase in size of group 2 means that $\gamma$ is constant while $\delta$ increases. Because the real payoff distributions of the assets are unaffected, equation (13) implies that all assets that have a positive covariance with the boycott factor (also unaffected) will have lower prices and, accordingly, higher expected returns in equilibrium.

The boycott risk premium is predicated on the arbitrage by the unrestricted and this fact causes the risk premia of individual assets to depend on the payoff distribution rather than just the sin content (zero-one in this simple model) - it is the asset's covariance with the risk factor that matters rather than the sin characteristic of the asset.

The boycott risk premium, $\mu_{b}$, can be derived from equation (8) and the construction of the boycott factor as $x_{b}-p_{b} \equiv \overline{\mathbf{n}}_{\mathbf{B}}^{\prime}(\mathbf{x}-\mathbf{p})$. Taking expected value we have $\bar{x}_{b}-p_{b}=(\gamma+\delta) \Sigma_{b}$, with $\Sigma_{b}=\overline{\mathbf{n}}_{\mathbf{S}}^{\prime}\left(\Sigma_{\mathrm{S}}-\Sigma_{\mathrm{SN}} \Sigma_{\mathbf{N}}^{-1} \Sigma_{\mathrm{NS}}\right) \overline{\mathbf{n}}_{\mathrm{S}}$ which is a quadratic form and thus positive. Since we can write the mean return as $\mu_{b}=\left[\left(\bar{x}_{b}-p_{b}\right) / p_{b}\right] / P_{f}$ we have

$$
\mu_{b}=\frac{(\gamma+\delta) \Sigma_{b}\left(1+R_{f}\right)}{\bar{x}_{b}-(\gamma+\delta) \Sigma_{b}}
$$

\footnotetext{
${ }^{5}$ The degree of absolute risk aversion depends on expected first and second wealth derivatives which may vary endogenously in our model. To guarantee exactly identical levels of risk aversion for both investor groups we may assume constant absolute risk aversion utility here, with identical constants of absolute risk aversion for both investor types.
} 
As the denominator, $p_{b}=\bar{x}_{b}-(\gamma+\delta) \Sigma_{b}$, is positive it is clear that $\mu_{b}$ : (a) is always positive; and (b) increases in $\delta$.

Consider now again the impact of an increase in the number of investors that boycott certain stocks. Then $q_{2}$ increases and $q_{1}$ decreases one-for-one. Given again that the basic risk aversion of both groups is equal so that $\theta=\theta_{1}=\theta_{2}, \gamma$ is unchanged, but $\delta$ increases (see the definitions below equation 8). The risk premium on the boycott beta increases because the smaller group of arbitrageurs must absorb more boycotted shares, implying a further tilt in their portfolios towards boycotted stocks and requiring a larger risk premium beyond the regular market risk premium. ${ }^{6}$

\section{From Theory to Measurement}

We can now test this two-factor CAPM by finding the appropriate factor proxies and by specifying the test assets. The boycott factor $r_{b}=(\mathbf{x}-\mathbf{p})^{\prime} \overline{\mathbf{n}}_{\mathbf{b}} / P_{b}$ can be well approximated by choosing a value-weighted portfolio of stocks that are boycotted, in the sense of being screened by many Socially Responsible Investing funds, to represent the theoretical concept of the valueweighted portfolio return of all stocks shunned by morally guided investors. In order to work with test assets that display variation in the boycott betas, we rely on industry portfolios which have mean returns that are notoriously hard to explain with standard asset pricing models (see for

\footnotetext{
${ }^{6}$ While the model generates a second factor, it is doubtful that this factor would make a major difference in pricing all test assets. Any diversified portfolio that is not particularly selected along dimensions of social acceptability of the real activities of the underlying assets (selection based on statistical criteria or typical firm characteristics) will likely end up with zero or close to zero boycott betas. Harvey, Liu, and Zhu (2014) expand on the issue of data snooping and publication biases to argue that the hurdle for accepting new risk factors should be high. While this is reasonable in general, the implication that finance research has uncovered too many risk factors, is not warranted, at least not in the present context: simple non-homogeneities across groups of investors are quite common (e.g., location, age, tastes, market access, tax circumstances, employment risk, family situation). Theoretically, these give rise to new risk factors along the lines of the above model. However, they are not likely to be pervasive, in the sense of requiring careful construction of test assets to be identified. If the issue is whether a particular finding of an anomaly, just as clearly subject to data snooping or publication biases, can be explained as a reward for risk or not, it does not make sense to increase the hurdle for identifying a risk factor.
} 
instance Lewellen, Nagel, and Shanken 2009, hereafter LNS). These industry portfolios, moreover, are likely to display significant variation in the nature of their real activities and, accordingly, should differ along the dimension of moral and social desirability.

LNS emphasize that a good fit in multifactor models is superficial if the test assets have a strong factor structure. As long as the factors correlate with the common sources of variation in the returns, loadings on proposed factors will explain the cross-sectional returns well, even if the empirical factors are mostly unrelated to the true factors. They propose to augment the popular 25 Fama-French portfolios sorted by size and book-to-market values with additional test portfolios that have weaker factor structures, sorted, for example by beta, firm characteristics, or by industry affiliation. But Lo and MacKinlay (1990) suggests that sorting on beta and other interesting characteristics known to be correlated with returns generates a data-snooping bias. This bias is exacerbated as more researchers sort on multiple characteristics, and consequently form a larger number of portfolios (Conrad, Cooper, and Kaul 2003). In contrast, sorting by industry affiliation is based on the nature of the firms' business and does not fall into the datasnooping trap.

Additionally, it is important to understand that our model does not stipulate a new factor that prices all portfolios. The boycott factor is relevant only for pricing portfolios that differ systematically in their loadings on this factor. Typical well-diversified portfolios, be they sorted by beta, size, value, or momentum, for instance, are unlikely to display clear differences in their boycott factor loadings. However, most of the social screens are industry-based - for example tobacco, gaming, alcohol - and accordingly industry portfolios ought to display significant differences in their exposure to the boycott factor. Industry portfolios, furthermore, do not have a strong factor structure and tend to generate larger dispersion in average returns, and hence 
present a challenge to any asset testing model. In fact, the test results of most existing asset pricing models do not hold up well when industry portfolios are included (See LNS, Table 1).

We employ the Black-Jensen-Scholes (1972) and Fama-MacBeth (1973) two-pass "beta" approaches to estimate our two-factor model and compare it against other models. The standard errors of this approach are biased depending on the severity of the cross-sectional correlation on the portfolio returns and measurement errors in the first-pass betas. To address the measurement error issue and to correct for serially correlated and/or heteroskedastic errors we also report the GMM t-statistics.

The evaluation criteria are primarily based on LNS (2009). Our model predictions are the following. First, the sign of the coefficient estimates on the boycott beta should be positive as predicted in our model. Second, the risk premium magnitudes for the market and boycotting factor portfolio should be close to their average excess returns. Third, the difference between realized and predicted portfolio returns should be zero on average. This is equivalent to verifying that the estimated second-pass intercept is zero, and may be interpreted as an indication that the risk-free asset is priced correctly. Fourth, by adding boycott factor betas in the second pass, the adjusted $R^{2}$ in our two factor model should show a significant improvement over competing models. Fifth, a proper model should in principle yield the same risk premium for any set of test assets. Thus, in alternately employing various test portfolios we will compare the magnitudes of the implied factor risk premiums. Sixth, while informal individual restraint in holding controversial stocks may have existed for a long time, formally announced explicit social screens were not prominent until the late 1990s. Therefore, the boycott risk premium is expected to be higher when a recent sample is used. 


\section{Data}

We employ two versions of the boycott factor: the narrow version based on all alcohol, coal, and tobacco firms; the broad version based on all alcohol, fossil fuel, gaming, weapons, and tobacco firms. Instead of using NAICS-based industry selection criteria, we identify the appropriate firms from SIC codes which allows us to extend backward the data period for better comparison with other asset pricing models. We construct the value-weighted boycott return as,

$$
r_{b t}=\frac{\sum_{i=1}^{N} p_{i t-1} I_{i t-1} r_{i t}}{\sum_{i=1}^{N} p_{i t-1} I_{i t-1}}
$$

$I_{i t-1}$ and $p_{i t-1}$, respectively, are the zero-one variable indicating whether asset $i$ is in the boycott portfolio (i.e., screened according to either the narrow or the broad criterion), and the market value of stock $i$ in the previous month. $r_{i t}$ is the monthly excess stock return of asset $i$. The monthly boycott factor begins in January 1963 and ends in December 2012. Summary statistics are presented in Table 4.

The popularity of social responsibility investment funds increased sharply since the mid1990s, as based on the screen usage reported in Social Investment Forum (2012). After 1999, funds employing screens crossed the $\$ 1$-trillion threshold, which is about $10 \%$ of the total wealth under professional management based on the Thomson Reuters Nelson tracked assets, as shown in Table 1.

The stock return data for the boycotted firms are obtained from the CRSP Monthly Stock File using the SIC codes associated with the relevant screens. We admit all stocks listed on the NYSE, AMEX, and NASDAQ between 1963/01 and 2012/12. Throughout, we exclude ADRs, REITs, closed-end funds, and primes and scores (share type code of 10 or 11). The test assets are 
the 30 (FF30) and 48 (FF48) value-weighted industry portfolios provided by Kenneth French. The market excess return and size, value, and momentum risk factors are also from Kenneth French's website. For ease of interpretation we remove the correlation with the market excess return from the boycott measure in equation (15) to generate the empirical measure of the boycott factor return.

\section{Results}

Table 5 presents the empirical comparison between our boycott-augmented model, the CAPM, the Fama-French three-factor model, and the Carhart four-factor model. The BoycottCAPM is given in equation (11). To further illustrate the impact of the boycott behavior on cross-sectional returns, we augment the Fama-French and the Carhart specifications with the boycott factor. We first consider the period since January 1999 for which the boycott impact is likely to be clearest. ${ }^{7}$

\section{The Boycott Risk Premium}

As stated in the theory section the boycott premium should be positive. The estimated boycott risk premium coefficient in Table 5, Panel A confirms this prediction for the FF30 portfolios. The estimated monthly boycott risk premium is $1.33 \%$, implying an annualized factor risk premium of around $16 \%$, which is twice as large as the market risk premium. This implies that stock returns are actually rewarded more for their associations with boycott risk than for

\footnotetext{
${ }^{7}$ The period January 1999 - December 2012 includes 168 months. While SRI funds existed before 1999 (see Table 1) it is important to avoid including a transition period in our sample during which the boycott premium increased substantially as this would imply falling prices, generating spuriously low average returns.
} 
market risk. This number is quite high but of similar magnitude as the excess sin returns found by $\mathrm{FMO}^{8}$

The magnitude of the boycott risk premium is further similar to the average excess boycott factor returns presented in Table 4. The difference between the Boycott-CAPM implied risk premium and the average excess boycott factor is $0.56 \%$ per month, sizeable but not of the orderof-magnitude difference that should raise a red flag, following LNS. The boycott factor is not only economically important, but also is statistically significant at the $5 \%$ level.

The empirically observed risk-adjusted sin stock abnormal returns can be reconciled with the positive boycott risk premium presented in our results. To see this intuitively we infer from equation (11) that

$$
\frac{\partial\left(\mu_{i}-\beta_{i m} \mu_{m}\right)}{\partial \beta_{i b}}=\mu_{b}>0, \quad \forall i
$$

The numerator is interpreted as the risk-adjusted abnormal return if the basic CAPM applies. In the investment world, this abnormal return is what a "vice fund" typically would brag about. Equation (16) states that the risk-adjusted abnormal return is an increasing function of the stock's sensitivity to the boycott factor. Trivially, if a vice fund only picks sin stocks its fund index will be highly correlated with the boycott factor, implying a high $\beta_{i b}$. Consequently, a vice fund is expected to beat the market index which has a relatively low $\beta_{m b}$. Table 6 , Panel A confirms this observation by showing that the tobacco, alcohol and coal industries are indeed very sensitive to the boycott factor, with boycott betas of $1.20,0.33$, and 0.64 , respectively. If the stocks' excess

\footnotetext{
${ }^{8}$ The economic significance of the boycott risk premium depends on the dispersion of the boycott sensitivities across assets. For the quintile of industries with the highest boycott betas, the average boycott beta is around 0.55 and for the quintile with the lowest, the average boycott betas is around -0.12 . Thus, the annualized expected return difference between these quintiles based on their boycott sensitivities is around $11 \%$ (16\% times 0.67$)$.
} 
returns were boycott-risk adjusted, the abnormal return should disappear. The relatively small and insignificant intercept of $-0.29 \%$ for the boycott-augmented CAPM in Table 5 supports this claim.

\section{Model Comparisons}

Table 5, Panel A presents the six models, three of which are boycott-factor-augmented. The Carhart model (FF4) has the highest $R^{2}$ among the three competing base models. Nevertheless, when the FF4 factors are augmented with the boycott factor, the adjusted $R^{2}$ improves by more than $10 \%$. The most noticeable $R^{2}$ improvement is when the boycott factor is added to the CAPM model. The boycott factor addition raises the $R^{2}$ by almost $50 \%$. This is a substantial improvement compared to a negative adjusted $R^{2}$ for the CAPM model. A similar improvement is observed when the boycott factor is added to the FF3 model. In both cases, the boycott factor is significantly positive at the $5 \%$ level, and all other factors are insignificant, reflective of the poor performance of traditional factor models in explaining the mean return differences across industry portfolios.

The improved explanatory power for expected return differences is further accompanied by decreases in the intercepts. Whenever the boycott factor is included in a model, the second-pass intercept is generally about $0.15 \%$ per month closer to zero. The total decrease in the intercept is around $0.70 \%$ per month. This is approximately the amount that is elsewhere claimed as the sin stocks' abnormal returns (Salaber 2009 and FOM 2008).

In order to visually compare the performance of our boycott-augmented specifications against the other models, we plot the fitted expected returns, computed by using the estimated parameter values from the models, against the realized average monthly test portfolio returns 
(shown for the CAPM and FF4 models). When $\hat{\beta}_{i m}$ alone is used, the predicted expected returns show virtually no dispersion, whereas the actual average returns vary substantially across the 30 industry portfolios (Figure 1, top panels). The performance improves when $\hat{\beta}_{i b}$ is added (Figure 1, bottom panels).

\section{Alternative Test Assets}

As long as the portfolios have sufficient variation in their sensitivities to the risk factor, a good asset pricing model should yield the same risk premium regardless of the choice of test portfolios. Table 5, Panel B provides the implied risk premium when the FF48 industry returns are used as alternative test assets. The magnitudes of the market and boycott risk premiums are consistent across the different sets of test assets for all boycott-risk-enhanced model specifications. For the FF48 industry case, the boycott risk premium is a bit smaller, 1.23\% per month versus $1.33 \%$ per month for the FF30 industries. The boycott risk premia are again significant at the 5\% level. The intercepts are even closer to zero. These observations are again confirmed by similar improvements in the fit when the boycott factor is added.

When we add the FF25 size- and value-sorted assets to the FF30 portfolios in Table 5, Panel C, as suggested by LNS, we may expect the resulting FF55 test portfolios to perform relatively worse for our model because the FF25 assets are unlikely to have much dispersion in their boycott factor sensitivities. Somewhat surprisingly, the boycott risk premia continue to be significant (though only marginally for the augmented CAPM), with high R-square, and only slightly lower risk premia compared to the other test asset cases. Part of the reason for the unexpectedly strong performance of the boycott-augmented models in the FF55 assets case may be that selecting on value causes boycotted stocks, having relatively low prices, to be put in high book-to-market portfolios. Thus the value effect would arise here because value stocks tend to 
load more highly on the boycott factor. Panel B of Table 6 illustrates that, indeed, the boycott betas of high book-to-market portfolios are considerably larger for every size class compared to the boycott betas of low book-to-market portfolios.

\section{Extended Time Series}

While SRI screens became economically significant only in the late-1990s, it is probable that private boycotts, i.e., a decreased appetite for morally or socially undesirable stocks in particular industries, had a market impact well before that time. To investigate this possibility, we extend our sample back to 1963 . Table 5, Panels D, E, and F show that the results are quite similar for the FF30, FF48, and FF55 sets of portfolios, with sizable improvements in the Rsquares when the boycott factor is added, significant boycott factor risk premia, and small intercepts. The key difference is that the boycott factor risk premia, although again similar across specifications, are substantially smaller, about 40 percent of the size for the later period. The smaller boycott risk premium is consistent with our model given that, in the period before SRI became popular, a smaller fraction of investors (lower $q_{2}$ ) restricted itself from investing in sin stocks. Figure 2 illustrates the cross-sectional explanatory power of the CAPM and FF4 models (top panels) versus augmented CAPM and FF4 models (bottom panels) for the FF30 industry portfolios.

As the sample period extends to more than 50 years, the betas are unlikely to be stable. The change in social norms and passage of certain legislation, in addition to basic changes in operations over time, may change investors' perception on certain industries. See, for instance, Liu, Lu, and Veenstra (2011). Thus, we allow the betas to vary over time by using the FamaMacBeth approach of rolling estimation of betas with 60 previous monthly observations. The first cross-sectional betas are generated by using the sample period January 1963 - December 
1967, and the average risk premiums are for the period January 1968 - December 2012. The results are available from the authors. They are very similar for each group of test assets to those in Panels D, E, and F, in terms of magnitude and significance of the boycott risk premium, and in terms of explanatory power (R-square). The intercept, however, is larger in all cases but not statistically significant.

\section{Portfolios Sorted by Boycott Factor Loadings}

Our model shows that boycotts can increase targeted firms' investment hurdle rates (required returns), but also affect the hurdle rates of firms whose returns happen to be statistically positively correlated with targeted firms: stocks without the sin characteristic, that nonetheless have similar exposure to the boycott factor (maybe because of shared inputs or other un-priced common factors), ought to have similar returns. To explicitly illustrate this implication, we construct a portfolio of stocks that are clearly non-sin. We employ all sin criteria used by either practitioners or researchers and consider the union of all these criteria. The advantage of including all these criteria is that we avoid a gray area, so that remaining stocks that are statistically positively correlated with the boycott factor are clearly not sin stocks.

We remove all stocks that, either by SIC or NAICS code, are classified in any one of the eight screens listed in Table 3. Additionally, we identify the industry classifications of the stocks that were at any point in time included in the Vice Fund. ${ }^{9}$ For example, Playboy is part of the Vice Fund stock holdings and the SIC code of Playboy, 2721, is the industry classification. We consider the entire set of firms so classified as "sin" firms for this purpose.

\footnotetext{
${ }^{9}$ Vice Fund data is from Thomson Reuters Mutual Fund Holdings (S12 file - fund identifier 7386). The Vice Fund data starts from 2002 and provides updated holdings on a quarterly basis.
} 
Our "sin net" captures 2766 sin firms out of the 9912 firms that are admitted into our data set. Approximately $28 \%$ of the firms are filtered out by this extensive sin screen. We obtain boycott factor loadings for the remaining stocks (with superscript $N$ indicating non-sin stocks).

$$
\begin{gathered}
r_{i t}^{N}=\alpha_{i}+\beta_{1 i} M k t_{t}+\beta_{2 i} S M B_{t}+\beta_{3 i} H M L_{t}+\beta_{4 i} U M D_{t}+\beta_{5 i} r_{b t}+\varepsilon_{i t} \\
r_{p t}^{N}=\alpha_{p}+\beta_{1 p} M k t_{t}+\beta_{2 p} S M B_{t}+\beta_{3 p} H M L_{t}+\beta_{4 p} U M D_{t}+\epsilon_{p t}
\end{gathered}
$$

Non-sin stocks are ranked based on the sin factor loadings generated from equation (17). These stocks are assigned to five portfolios based on their individual rankings. The equal-weighted monthly mean excess returns are reported in Table 7, Panel A, for each of the five portfolios of non-sin stocks and also for five portfolios of sin stocks from the narrow boycott factor, similarly sorted by their boycott betas. In general, stocks that are more susceptible to the boycott factor have relatively higher monthly excess returns for both sin stocks and non-sin stocks. Predictably this pattern is not as strong as when sin stocks are included since we removed most of the stocks with high boycott factor loadings. This is clear by comparing in Panel A the boycott betas for the sin stocks (average boycott beta of 0.60 ) and the non-sin stocks (average boycott beta -0.05).

We then construct a zero-investment portfolio $p$ by taking a long position in the quintile of non-sin stocks that are most positively correlated with the sin factor and a short position in the least positively correlated quintile of non-sin stocks (those with the lowest correlation with the boycott factor). The zero-investment portfolio is regressed on the FF3 or FF4 (Carhart) risk factors as in equation (18). The results are in Table 7, Panel B and suggest that stocks that have clearly no sin characteristics nevertheless may earn a boycott risk premium if their returns happen to be correlated with sin stocks so that they have positive sensitivity to the boycott risk factor. The alpha is fairly sizable at around 5\% annualized, but only marginally significant. 


\section{Alternative Explanations}

The literature has provided several alternative theoretical explanations for the empirically identified sin premium and we would like to compare these explanations explicitly to the systematic boycott risk explanation proposed here. The alternative explanations are that sin firms or boycotted firms: (1) face more litigation risk (FMO 2008), (2) are less liquid (HK 2009), or (3) are neglected (Fang and Peress 2009 and HK 2009).

\section{Litigation Risk or Boycott Factor}

Our test portfolios are grouped by industrial affiliation. The dispersion of the average portfolio returns may purely be a reflection of industry specific characteristics. Thus, an industry fixed effect may explain a large portion of cross-sectional differences in these portfolio returns. Investors' particular dislike for some industries may give rise to these portfolios' higher average returns. Merton (1987) shows when investors have limited attention, that market beta is not the only source of risk and that idiosyncratic risk matters for pricing. This idiosyncratic risk is highlighted by the nature of the business. Businesses that have a negative environmental impact or do not conform to the social norms are more subject to litigation risks. The abnormal returns observed for sin firms in previous research may merely be a compensation for the idiosyncratic risk of operating in a legally hostile environment that matters in a Merton (1987) world. If this hypothesis is true, average industry test portfolios returns are mainly driven by the litigation risks associated with the business nature of these industries. This implies that the cross-sectional returns may potentially be influenced by a litigation "characteristic" instead of the systematic boycott risk factor predicted by our model.

To rule out the possibility that cross-sectional returns are driven by the idiosyncratic risk of litigation issues associated with each industry we construct a variable $L T G$, as a proxy for the 
litigation risk. Under Accounting Standards Codification Topic 450-20 "Loss Contingencies" (ASC 450-20), a company must create a litigation loss reserve if (1) a loss is probable and (2) the amount of the expected loss is material and reasonably estimable. ${ }^{10}$ For each FF30 or FF48 industry, we count the total non-missing number of After-Tax Settlement (Annual Item SETA in Compustat North American) entries (both Litigation and Insurance) and scale them by the total number of firm-year observations for this industry. This ratio is called $L T G$ and is used as a proxy for the litigation characteristic in an industry.

Two issues may potentially make this a noisy measure for the litigation risk. First, we are not able to identify the nature of each lawsuit. We are interested in lawsuits originating from the nature of firms' businesses. Lawsuits such as malpractice, financial class action, etc. have to be assumed to occur evenly across all industries. Second, some lawsuits may last longer than others and some settlement probabilities may be re-evaluated multiple times. So, lingering suits may overstate the count. There are two major advantages of using this proxy, however. First, it is conservative. The conditions for a SETA to be non-missing are quite strict. SETA is a special item in the income statement. Firms are not allowed to include a SETA entry in their accounts unless (1) lawsuits are filed and (2) loss is probable based on lawyers assessments. Second, the claims have to be larger than 10 percent of the company's current assets. This implies that any non-missing observations on SETA almost guarantee a substantial lawsuit initiated against the firm.

To test for the influence of the litigation "characteristic", we adopt the methodology employed by Jagannathan and Wang $(1996,1998)$. We include the constructed litigation variable $L T G$ as a proxy for a characteristic - the degree of sinfulness of an industry as revealed through

\footnotetext{
${ }^{10} \mathrm{http} / / /$ www.perkinscoie.com/news/pubs_detail.aspx?publication=1323\&op=updates
} 
litigation. If our boycott factor is indeed a systematic risk factor, this additional proxy for sinfulness or boycott risk should not explain any residual variation in average returns across the industry portfolios. On the other hand, if $\widehat{\beta}_{\mathrm{ib}}$ (the boycott beta) cannot stand up to a test against this cross-sectional variable, $L T G$, the systematic boycott factor should not be in the model.

Before we proceed to test if the boycott factor is a proper risk factor, we need to validate our proxy. Table 8 shows that the litigation variable is both economically and statistically significant: when the FF30 and FF48 portfolios are used as test assets, on average, if an industry's proportional number of law suits increases by $100 \%$, average monthly cross-sectional portfolio returns will increase by $5.5 \%$ and $4.3 \%$, respectively. Including the proxy also bring up the cross-sectional $\mathrm{R}^{2}$ by about $10 \%$ in both cases and significantly reduces the pricing errors. Thus, our litigation-based proxy $L T G$ appears to be a good indicator for the industry characteristics associated with the sin premium. The second model in Table 8 shows that when $\widehat{\beta}_{\mathrm{ib}}$ is added to the model, the t-values for the $L T G$ coefficients drop significantly from 2.05 to 0.32 when the FF30 portfolios are used and from 2.03 to 1.02 when the FF48 portfolios are used. The magnitudes of the characteristics coefficients - the $\delta_{\mathrm{i}, \mathrm{LTG}}$ coefficients - also decrease substantially in both cases. In contrast, the boycott factor risk premiums remain both economically and statistically significant. The magnitudes and t-values for $\widehat{\beta}_{\mathrm{ib}}$ are similar compared to those before $L T G$ was added. Therefore, we rule out the possibility that average industry portfolio returns are explained by litigation-risk-type characteristics as opposed to our systematic boycott risk factor. 


\section{The Illiquidity of Boycotted Stocks}

In this section we explore if the boycott risk premium we find may instead be a liquidityrelated phenomenon. Boycotted stocks have a smaller investor base: some investors, particularly morally constrained investors, do not hold these stocks in their investment portfolios. We argue that this fact causes arbitrageurs to hold these stocks in excess and that it is their concomitant increase in portfolio risk that generates the boycott risk premium. However, an alternative explanation is that the reduced investor base implies that in a liquidity-driven sell situation boycotted stocks will not be moved, unless there is a ready investor who happens to be "morally unconstrained".

There are other reasons for why boycotted stocks may be less liquid. One is that advertising to attract additional investors may be difficult for boycotted firms. Headline risk, as proposed by FMO (2008), refers to the risk that news stories about a controversial business, true or not, will always be interpreted as bad. In this sense norm-violating firms are better off operating quietly under the social radar. Second, the empirical work of HK (2009) suggests that sin firms tend to have fewer institutional investors compared to regular firms. Additionally, sin firms have less financial analyst coverage (sin firms are neglected). These findings suggest potentially less liquidity for boycotted stocks.

\section{Idiosyncratic liquidity measure}

To investigate the liquidity perspective that competes with our risk perspective, we follow Amihud (2002) in constructing a measure of illiquidity using data from the CRSP Daily Stock File. Amihud (2002) defines the illiquidity of stock $i$ in year $y$ as 


$$
I L L I Q_{y}^{i}=\frac{1}{D_{y}^{i}} \sum_{d=1}^{D_{y}^{i}} \frac{\left|R_{y d}^{i}\right|}{V_{y d}^{i}}
$$

with $R_{y d}^{i}$ and $V_{y d}^{i}$, respectively, the return and dollar volume (in millions) on day $d$ in year $y$, and $D_{y}^{i}$ the number of valid observation days in year $y$ for stock $i ; V_{y d}^{i}=\operatorname{Price}_{y d}^{i} * \operatorname{Vol}_{y d}^{i}$, with Vol $l_{y d}^{i}$ the trading volume in units of one share during day $d$ and Price $_{y d}^{i}$ the daily closing price on day $d$ in year $y$. The stocks in our sample are traded on the NYSE, AMEX, and NASDAQ between January 1, 1999 and December 31, 2012. Since average illiquidity varies considerably over time, Amihud (2002) adjusts ILLIQ $Q_{y}^{i}$ in his cross-sectional regression by its mean value, $A I L L I Q_{y}=\frac{1}{N_{y}} \sum_{i=1}^{N_{y}} I L L I Q_{y}^{i}$, with $N_{y}$ the number of firms. This yields

$$
I L L I Q M A_{y}^{i}=I L L I Q_{y}^{i} / A I L L I Q_{y}
$$

We use ILLIQMA $A_{y}^{i}$ as a measure of the illiquidity characteristic of a stock, regular or boycotted stocks. Stocks are included in the construction of the illiquidity measure if they satisfy the following Amihud (2002) criteria: (1) The stock price is greater than $\$ 5$ at the end of year $y$-1. (2) Every year, each stock has to have at least 200 valid return and volume observations. (3) Derivative securities like ADRs or foreign stocks and scores and primes are excluded from the sample. After constructing the illiquidity measure for each year, we winsorize illiquidity at the highest and lowest $1 \%$ tails of the distribution.

\section{Liquidity impact on returns}

We explore whether the boycott premium may be a liquidity-related phenomenon. If the lack of a broad investment base represents an arbitrage opportunity, it may only persist if large 
impediments prevent morally unconstrained investors from trading on it. "Illiquidity" might be one type of friction that prevents morally indifferent investors from arbitraging away the difference. The regular- and boycotted-stock return differential may be a compensation for "illiquidity" instead of the boycott premium claimed in section 6 .

To rule out the "illiquidity premium" explanation, we use Amihud (2002)'s illiquidity measure from equation (20) as a portfolio characteristic. As shown in Table 9, when we incorporate this illiquidity measure $I L Q$ as an industry cross-sectional characteristic in the second pass, the implied "illiquidity premium" is statistically insignificant and negative rather than positive as expected. This suggests that the industry specific "illiquidity" is not compensated and thus certainly cannot explain the boycott premium. Additionally, Table 9 shows that including the illiquidity characteristic $I L Q$ does not affect the level and significance of the boycott risk premium.

\section{Systematic liquidity risk}

An alternative mechanism by which liquidity may affect returns is via the Pastor-Stambaugh traded liquidity factor serving as an aggregate liquidity risk factor. Boycotted firms being presumably less liquid may have higher sensitivity to an aggregate market liquidity factor. If an industry portfolio only delivers higher returns when market liquidity is high, the marginal utility of wealth will be lower. Stocks whose highest returns occur when market liquidity is high will require higher rates of return. If boycotted stocks (or any stocks that have positively correlated returns with boycotted stocks) have larger exposures to market liquidity, higher risk premiums would be driven by these stocks' sensitivities to aggregate liquidity instead of their sensitivities

\footnotetext{
${ }^{11}$ This idea of friction is borrowed from the "Impediments to Trade" hypothesis proposed in Fang and Peress (2009).
} 
to the boycott factor. If this hypothesis is true, we expect to see that expected stock returns shall be attributed to the liquidity factor loadings as opposed to the boycott factor loadings.

The second-pass results in Table 10 show that the systematic liquidity factor $S L Q$ has significant explanatory power for explaining bot the FF30 and FF48 test assets. However, the boycott factor continues to have significant marginal explanatory power for these test assets. Neither the sensitivity to liquidity nor the boycott factor sensitivity muffles the importance of the other. When one factor is added to the model, the economic importance of the other factor decreases somewhat. The addition of the boycott factor dramatically lowers the intercept which is not the case when the liquidity factor is added. Including both the liquidity and the boycott factor with the CAPM generates an R-square of $76 \%$ for the FF30 test assets, and $64 \%$ for the FF48 test assets. Thus, while market liquidity risk appears to be separately relevant in pricing the industry portfolios, it does not diminish the importance of boycott risk.

\section{Neglect Effect or Systematic Risk}

Merton (1987) attributes a divided investor base to the investors' concern about asymmetric information among investors. When a firm releases public information to both current and potential shareholders, the effective information received by current shareholders will not be the same as that received by potential investors. Current investors are supposedly more informationally engaged with the stocks they own because of the sunk cost that they have incurred. For a potential investor, the fear of being taking advantage of in conjunction with the fixed cost necessary to obtain information will cause typical investors to follow only a subset of traded stocks. Merton divides the information costs into two parts: (1) the cost of transmitting information from one party to another and (2) the cost of gathering and processing information. 
Increases in either type of information costs cause a firm to be followed by fewer investors which leads to it require a higher return in Merton's view.

The impact of costs of transmitting information has been studied by Fang and Peress (2009). They find that stocks not covered by media earn significantly higher future returns than stocks that are heavily covered. Barber and Odean (2008) show that individual investors are net buyers of attention-grabbing stocks. Investors often face difficulties in choosing which stocks to buy from a large pool of stocks. Thus, attention-grabbing stocks are more likely to enter their choice set. As suggested in FMO (2008), sin stocks tend to suffer "headline risk". Sin industries are constantly under public scrutiny, so that news is almost always interpreted as bad. Therefore, sin stocks are better off staying away from the public media. Consequently, attention-avoiding sin stocks are expected to have higher "media" premiums.

Information gathering and processing is generally conducted by financial analysts. If a firm is followed by relatively more analysts, the quality of information for a more heavily covered firm is expected to be higher than for a less covered firm. As sin stocks are followed by fewer financial analysts (see HK 2009), observed higher sin stock returns might merely be a compensation for the poor information available for this firm, and it would be the neglect effect that gives rise to the higher sin-stock abnormal returns. Arbel, Carvell, and Strebel (1983) find that the neglected firm effect persists after the usual adjustment for risk, and this effect is robust across firm size classes. Although the reason for sin stocks being neglected here is different from that in Arbel et al. the outcome of particular stocks being screened from the investment universe of certain investors is the same. The research concentration of analysts is dictated by institutions' predilections. Therefore, as long as social screens exist, the neglect premium should persist. Under the light of less institutional ownership on sin stocks, persistent higher sin stock returns 
are consistent with the finding in Hong, Lim, and Stein (2000) that stocks lightly covered tend to have higher average returns than heavily covered stocks. To rule out the possibility that crosssectional returns are driven by this neglect effect instead of the systematic boycott factor, we construct analyst coverage as a proxy for the neglect effect. ${ }^{12}$

We first obtain stock return data from the CRSP Monthly Stock File (MSF). We include NYSE, AMEX, and Nasdaq stocks and exclude ADRs, REITs, closed-end funds, and primes and scores. The data on analyst coverage are from the IBES History Summary File (STATSUM_EPSUS). All these data are available on a monthly basis. For each stock in CRSP, we set the coverage variable for any given month equal to the number of IBES estimates providing one-year-ahead earnings per share forecasts. If no IBES value is available, we set the coverage variable to zero. ${ }^{13}$

For each industry, we take the log of the total number of analysts in this industry scaled by this industry's market capitalization. We use this ratio as a proxy for the analyst coverage. The top three least covered industries among the FF30 industries are tobacco, coal and alcohol (not shown). The overall ranking by analyst coverage is consistent with the results reported by HK (2009) that sin industries are less covered by financial analysts.

Table 11 shows that our constructed analyst coverage ratio, $\delta_{i c}$, is a good proxy for the neglect effect. The significant negative estimated coefficient in equation 1 of Table 11 on the coverage ratio is consistent with the HK results: the asymmetric information issue is alleviated by analyst coverage. The expected payoff will not be discounted as much as when there is no coverage at all. The estimated coefficient, -0.15 , means that when the number of analysts

\footnotetext{
${ }^{12}$ Even though it might be expected that sin industries are more closely monitored by the government or the public media, Fang and Peress (2009), p. 2030 find that the extent of media coverage is virtually identical across industries.

${ }^{13} \mathrm{We}$ follow Hong, Lim, and Stein (2000) in constructing the analyst coverage proxy.
} 
(adjusted by market cap) increases by $1 \%$, the expected return in this industry, on average, will decrease by 0.15 percent per month. This negative risk premium is also statistically significant. This suggests that the neglect effect as an industry characteristic affects equity pricing.

However, when we add the boycott factor loadings into the CAPM along with the coverage ratio, the boycott factor dominates. The neglect effect is statistically subsumed by the boycott factor. The "transparency" supposedly increased by analyst coverage no longer decreases the required rate of return. The significance and magnitudes of the boycott risk premium continue to be quite consistent across all specifications. This suggests that our boycott factor is indeed a systematic risk factor, overshadowing the characteristic based risk source suggested by Hong and Kacperczyk (2009, p.17).

\section{The Broad Boycott Factor}

To examine the robustness of our results with respect to the choice of boycotted industries, we consider the broader version of the boycott factor based on screening all alcohol, fossil fuel, gaming, weapons, and tobacco firms. As shown in Table 2, this amounts to an annual average number of around 200 boycotted firms. Table 3 shows that the broader boycott factor BCTb has a correlation with the narrower boycott factor BCTn of $62 \%$ for the January 1999 - December 2012 period. Its mean return is a larger $1.21 \%$ a month compared to $0.77 \%$ for BCTn.

Table 12 shows that the results replacing the narrow boycott factor BCTn by the broader boycott factor $\mathrm{BCTb}$ are little different. The magnitude and significance of the boycott risk premium is similar, and so is the R-square and the intercept, for each of the FF30, FF48, and FF55 test assets, compared to the results in Table 5. 


\section{Conclusion}

The elegant result of two-fund separation is based on several critical assumptions, including that investors have identical investment opportunities. However, if social screens are prevalent in economically relevant measure, this assumption is violated. Boycotted stocks are not available to a group of morally constrained investors, who face a reduced investment opportunities set. The violation of the identical investment opportunities assumption gives rise to an additional source of risk-a boycott risk factor: absorption of boycotted stocks by unconstrained investors requires compensation for the extra risk of holding these stocks in excess of the otherwise efficient weights.

We derive a boycott-augmented CAPM by explicitly segregating the investor base into two groups based on their moral constraints. The model implies that the risk premiums of any stocks are linear combinations of the market and boycott risk factors and sheds light on the commonly observed risk-adjusted abnormal return on sin stocks. By incorporating the boycott risk factor, this abnormal return disappears. The perceived superior performance of sin stocks identified in previous studies is because of their close association with the boycott factor.

In a two-stage cross-sectional regression framework, we evaluate the Boycott-CAPM, CAPM, FF3 and FF4 models by considering the incremental contribution of the proposed boycott factor to the model's overall explanatory power. We find that the boycott risk premium is both theoretically and empirically positive. The magnitude of the boycott risk premium is generally close to the average return of the portfolio of boycotted stocks regardless of the choice

of the test assets. Furthermore, while the boycotted firms face beyond-normal litigation risk, neglect, and illiquidity, the boycott risk premium cannot be driven out by the litigation risks 
suggested by HK (2009), the neglect effect of Merton (1987), and measures of idiosyncratic liquidity (Amihud, 2002) or systematic liquidity exposure (Pastor and Stambaugh, 2003).

The boycott factor results provide a strong indication that non-pecuniary preferences regarding the underlying activities funded by securities may have pervasive pricing effects. Distaste for particular activities systematically reduces the demand for financing these activities, exerting downward price pressure on the securities. Risk arbitrage by unencumbered investors is limited by the specific risk of these securities, causing the prices of any securities with comparable risk characteristics, but potentially unrelated underlying activities, to be affected as well. The boycott event here represents a measurable instance of reduced demand for nonpecuniary reasons. The risk factor prices an otherwise un-priced risk, akin to the idiosyncratic risk that becomes priced in the Merton (1987) context with the assumption of uncorrelated returns, but here becomes a systematic risk component because returns are allowed to be correlated. 


\section{Appendix}

\section{Unrestricted investors}

Investor type 1 represents the representative morally unrestricted investor. In the traditional single-period CAPM setting, the terminal wealth of the unconstrained investor is fully consumed: $c_{1}=w_{1}$, with $w_{1}$ the end of period wealth of the unrestricted investor. The investment problem of an unrestricted investor under the aforementioned assumptions is as follows:

$$
\underset{\mathbf{n}_{1}}{\operatorname{Max}} E\left[U\left(w_{1}\right)\right], \text { s.t. } \quad w_{1}=\left(\bar{w}_{1} / P_{f}\right)+\mathbf{n}_{1}^{\prime}(\mathbf{x}-\mathbf{p}) .
$$

The wealth constraint follows from $w_{1}=\mathbf{n}_{1}^{\prime} \mathbf{x}+n_{1}^{f}$, where $\mathbf{n}_{\mathbf{1}}$ is a vector representing the number of shares investor 1 purchases in each of the $N$ existing risky assets, and $\mathbf{x}$ is the vector of payoffs per share in each of the $N$ risky assets; $n_{1}^{f}$ is the number of risk free discount bonds with unit payoff purchased by investor 1 , and $\bar{w}_{1}=\mathbf{n}_{1}^{\prime} \mathbf{P}+n_{1}^{f} P_{f}$, where $\bar{w}_{1}$ is the initial wealth of investor $1, \mathbf{P}$ the vector of prices of the risky assets, and $P_{f}$ the price of the discount bond. The constraint in (1) is obtained by eliminating $n_{1}^{f}$ from the initial and final wealth equations and defining $\mathbf{p}=\mathbf{P} / P_{f}$. The first-order conditions for the investment choices of the unrestricted investors from (1) are

$$
E\left[U^{\prime}\left(w_{1}\right)(\mathbf{x}-\mathbf{p})\right]=0 .
$$

Under the assumption that payoffs $\mathbf{x}$ are multivariate normally distributed we may apply Stein's Lemma after using the definition of covariance in equations (2) to obtain:

$$
\overline{\mathbf{x}}-\mathbf{p}=\theta_{1} \mathbf{\Sigma} \mathbf{n}_{1}
$$


where $\theta_{1}=-E\left[U^{\prime \prime}\left(w_{1}\right)\right] / E\left[U^{\prime}\left(w_{1}\right)\right]$ is akin to the degree of absolute risk aversion of the unconstrained investor, which will depend on initial wealth of investor 1 and other model parameters (unless we assume CARA utility). The covariance matrix of the payoffs for the risky assets is given by $\boldsymbol{\Sigma}$ and the expected payoffs of the risky assets are represented by $\overline{\mathbf{x}}$.

\section{Morally guided investors}

The investment decision problem for the representative morally guided investor, investor type 2, is similar except that this investor chooses to boycott what is considered to be "sin" stocks - stocks issued by firms whose activities this investor finds morally or socially unacceptable. Final perceived consumption/wealth for investor 2 is given now by $w_{2}=\mathbf{n}_{2}^{\prime} \mathbf{x}+n_{2}^{f}$. Given $\bar{w}_{2}=\mathbf{n}_{2}^{\prime} \mathbf{P}+n_{2}^{f} P_{f}$ investor 2's decision problem is

$$
\operatorname{Max} E\left[U\left(w_{2}\right)\right], \text { s.t. } \quad w_{2}=\left(\bar{w}_{2} / P_{f}\right)+\mathbf{n}_{2}^{\prime}(\mathbf{x}-\mathbf{p}) \text {, }
$$

where $\mathbf{n}_{2}$ is a vector representing the number of shares investor 2 purchases in only the $N_{N}$ risky assets that are not morally objectionable. The first-order conditions for investor 2 are

$$
E\left[U^{\prime}\left(w_{2}\right)(\mathbf{x}-\mathbf{p})\right]=0
$$

leading to

$$
\overline{\mathbf{x}}_{\mathbf{N}}-\mathbf{p}_{\mathbf{N}}=\theta_{2} \mathbf{\Sigma}_{\mathbf{N}} \mathbf{n}_{2}
$$

where the matrix of asset payoff covariances is partitioned into those related to "sin stocks" from morally objectionable firms (S) and non-sin (N) firms: $\quad \boldsymbol{\Sigma}=\left(\begin{array}{cc}\boldsymbol{\Sigma}_{\mathrm{N}} & \boldsymbol{\Sigma}_{\mathrm{NS}} \\ \boldsymbol{\Sigma}_{\mathrm{SN}} & \boldsymbol{\Sigma}_{\mathrm{S}}\end{array}\right)$ so that $\boldsymbol{\Sigma}_{\mathrm{N}}$ represents 
the payoff covariance matrix of all stocks that are not boycotted and $\overline{\mathbf{x}}_{\mathrm{N}}, \mathbf{p}_{\mathrm{N}}$ are the vectors of mean payoffs and prices, respectively, of the non-boycotted assets.

\section{Market equilibrium}

Assuming that there are $q_{1}$ investors of type 1 and $q_{2}$ investors of type 2 , the demand for assets may be obtained and set equal to the exogenous supply of shares, $\overline{\mathbf{n}}=\left(\begin{array}{l}\overline{\mathbf{n}}_{\mathbf{N}} \\ \overline{\mathbf{n}}_{\mathrm{S}}\end{array}\right)$, and zero for the risk free asset, yielding the conditions for market equilibrium:

$$
\overline{\mathbf{n}}=q_{1} \mathbf{n}_{1}+q_{2} \mathbf{n}_{2}, \quad 0=q_{1} n_{1}^{f}+q_{2} n_{2}^{f}
$$

Substitute the demands for shares by both types of investors obtainable from equations (3) and (6) into market equilibrium equation (7) and solve as shown in the Appendix to obtain the solution for excess payoffs:

$$
\overline{\mathbf{x}}-\mathbf{p}=\gamma \mathbf{\Sigma} \overline{\mathbf{n}}+\delta \Sigma \overline{\mathbf{n}}_{\mathbf{B}}
$$

with $\overline{\mathbf{n}}_{\mathbf{B}}$ a "boycott" portfolio of shareholdings $\overline{\mathbf{n}}_{\mathbf{B}}=\left(\begin{array}{c}-\Sigma_{\mathbf{N}}^{-1} \Sigma_{\mathbf{N S}} \overline{\mathbf{n}}_{\mathbf{S}} \\ \overline{\mathbf{n}}_{\mathbf{S}}\end{array}\right)$, and $\gamma=\frac{1}{\left(q_{2} / \theta_{2}\right)+\left(q_{1} / \theta_{1}\right)}$ and $\delta=\gamma\left(q_{2} / \theta_{2}\right) /\left(q_{1} / \theta_{1}\right)$. As follows from the interpretation in Errunza and Losq (1985) translated to our alternative context, the boycott portfolio consists of two components: long the value-weighted portfolio of sin stocks and short a hedge portfolio of non-sin stocks designed to offset as much as possible of the risk of the sin portfolio. The price of the boycott factor, $P_{b}=\overline{\mathbf{n}}_{\mathbf{B}}^{\prime} \mathbf{P}$ is positive. This must be true in general equilibrium because the boycott portfolio represents the value of the payoffs from sin stocks after hedging the payoffs that are already 
covered by the market. Since the sin stocks could not otherwise exist in positive supply (at least not in our one-period context) the value of the residual payoffs must be positive.

To convert equation (8) into an expression for mean returns rather than expected net payoffs, consider that the gross stock returns equals $1+r_{i}^{s}=x_{i} / P_{i}$. Therefore, $x_{i}-p_{i} \equiv x_{i}-\left(P_{i} / P_{f}\right)$ equals $P_{i}\left(r_{i}^{s}-r_{f}\right)$ because $P_{f} \equiv 1 /\left(1+r_{f}\right)$. Define the excess return as $r_{i} \equiv r_{i}^{s}-r_{f}$ and the mean excess return as $\mu_{i} \equiv \mu_{i}^{s}-r_{f}$. Since $1+r_{i}^{s}=x_{i} / P_{i}$ the covariance matrix of risky asset returns $\boldsymbol{\sigma}$ is related to the covariance matrix of risky asset payoffs $\Sigma$ such that for a specific element $\sigma_{i j}$ of this matrix we have that $\sigma_{i j}=\Sigma_{i j} / P_{i} P_{j}$. Then we can write for a particular element of the vector in equation (8):

$$
\mu_{i}=\gamma P_{m} \sigma_{i m}+\delta P_{b} \sigma_{i b}
$$

where $m$ represents the market, $P_{m}=\bar{w}_{1}+\bar{w}_{2}$ is the cost of the market portfolio, and $P_{b}$ the cost of the boycott portfolio. Apply equation (9) to the market portfolio and the boycott portfolio to obtain equations for $\mu_{m}$ and $\mu_{b}$ :

$$
\mu_{m}=\gamma P_{m} \sigma_{m}^{2}+\delta P_{b} \sigma_{m b}, \quad \mu_{b}=\gamma P_{m} \sigma_{b m}+\delta P_{b} \sigma_{b}^{2}
$$

Then solve equations (10) for $\gamma P_{m}$ and $\delta P_{b}$, and substitute the resulting expressions into equation (9) to generate the two-factor result

$$
\mu_{i}=\beta_{i m} \mu_{m}+\beta_{i b} \mu_{b}
$$

where $\beta_{i m}, \beta_{i b}$ are the population values of the slope estimates for a linear regression of the return of asset $i$ on the market portfolio return and the boycott portfolio return: 


$$
\beta_{i b}=\frac{\sigma_{i b} \sigma_{m}^{2}-\sigma_{i m} \sigma_{m b}}{\sigma_{b}^{2} \sigma_{m}^{2}-\sigma_{b m}^{2}}, \quad \beta_{i m}=\frac{\sigma_{i m} \sigma_{b}^{2}-\sigma_{i b} \sigma_{m b}}{\sigma_{b}^{2} \sigma_{m}^{2}-\sigma_{b m}^{2}}
$$

Solving for the risky asset demands of both groups from equations (3) and (6) gives

$$
\mathbf{n}_{1}=\left(\theta_{1} \Sigma\right)^{-1}(\overline{\mathbf{x}}-\mathbf{p}), \mathbf{n}_{2}=\left(\theta_{2} \Sigma_{\mathbf{N}}\right)^{-1}\left(\overline{\mathbf{x}}_{\mathbf{N}}-\mathbf{p}_{\mathbf{N}}\right)
$$

and substituting into equation (7) yields:

$$
\overline{\mathbf{n}}=\left[\left(\boldsymbol{\Sigma} \theta_{1} / q_{1}\right)^{-\mathbf{1}}+\left(\begin{array}{l}
\mathbf{I} \\
\mathbf{0}
\end{array}\right)\left(\boldsymbol{\Sigma}_{\mathbf{N}} \theta_{2} / q_{2}\right)^{-\mathbf{1}}\left(\begin{array}{ll}
\mathbf{I} & \mathbf{0}
\end{array}\right)\right](\overline{\mathbf{x}}-\mathbf{p})
$$

A standard inversion identity states that given matrices $\mathbf{X}_{1}, \mathbf{X}_{2}, \mathbf{X}_{3}$, and $\mathbf{X}_{4}$, with $\mathbf{X}_{1}$ and $\mathbf{X}_{4}$ invertible, we have (see, for instance, Söderström 1994, pp. 156-157):

$$
\left(\mathbf{X}_{1}+\mathbf{X}_{2} \mathbf{X}_{4}^{-1} \mathbf{X}_{3}\right)^{-1}=\mathbf{X}_{1}^{-1}-\mathbf{X}_{1}^{-1} \mathbf{X}_{2}\left(\mathbf{X}_{4}+\mathbf{X}_{3} \mathbf{X}_{1}^{-1} \mathbf{X}_{2}\right)^{-1} \mathbf{X}_{3} \mathbf{X}_{1}^{-1}
$$

Use this identity to manipulate the inverse of the term in brackets in (A2):

$$
\begin{aligned}
& {\left[\left(\boldsymbol{\Sigma} \theta_{1} / q_{1}\right)^{-\mathbf{1}}+\left(\begin{array}{l}
\mathbf{I} \\
\mathbf{0}
\end{array}\right)\left(\boldsymbol{\Sigma}_{\mathbf{N}} \theta_{2} / q_{2}\right)^{-\mathbf{1}}\left(\begin{array}{ll}
\mathbf{I} & \mathbf{0}
\end{array}\right)\right]^{-\mathbf{1}}=} \\
& \left(\theta_{1} / q_{1}\right)\left[\boldsymbol{\Sigma}-\left(\frac{\left(\theta_{2} / q_{2}\right)}{\left(\theta_{1} / q_{1}\right)+\left(\theta_{2} / q_{2}\right)}\right) \boldsymbol{\Sigma}\left(\begin{array}{cc}
\boldsymbol{\Sigma}_{\mathbf{N}}^{-1} & \mathbf{0} \\
\mathbf{0} & \mathbf{0}
\end{array}\right) \boldsymbol{\Sigma}\right]
\end{aligned}
$$


Then we use the definitions $\overline{\mathbf{n}}_{\mathbf{B}}=\left(\begin{array}{c}-\boldsymbol{\Sigma}_{\mathbf{N}}^{-1} \boldsymbol{\Sigma}_{\mathbf{N s}} \overline{\mathbf{n}}_{\mathbf{S}} \\ \overline{\mathbf{n}}_{\mathbf{s}}\end{array}\right)$, together with $\gamma=\frac{1}{\left(q_{2} / \theta_{2}\right)+\left(q_{1} / \theta_{1}\right)}$ and $\delta=\gamma\left(q_{2} / \theta_{2}\right) /\left(q_{1} / \theta_{1}\right)$ to obtain equation (8) in the text:

$$
\overline{\mathbf{x}}-\mathbf{p}=\gamma \Sigma \overline{\mathbf{n}}+\delta \Sigma \overline{\mathbf{n}}_{\mathbf{B}}
$$




\section{References}

AHRENS, D. (2004): "Investing in Vice," St. Martin's Press, New York.

AMIHUD, Y. (2002): "Illiquidity and Stock Returns: Cross-Section and Time-Series Effects," Journal of Financial Markets, 5, 31-56.

ARBEL, A., S. CARVELL, and P. STREBEL (1983): "Giraffes, Institutions and Neglected Firms," Financial Analysts Journal, 39, 57-63.

BARBER, B. M., and T. ODEAN (2008): "All That Glitters: The Effect of Attention and News on the Buying Behavior of Individual and Institutional Investors," Review of Financial Studies, 21, 785818.

BLACK, F., M. JENSEN, and M. SCHOLES (1972): "The Capital Asset Pricing Model: Some Empirical Tests."

CARHART, M. M. (1997): "On Persistence in Mutual Fund Performance," Journal of Finance, 52, 57-82.

CHARI, V. V., R. JAGANNATHAN, and A. R. OFER (1988): "Seasonalities in Security Returns - the Case of Earnings Announcements," Journal of Financial Economics, 21, 101-121.

CHONG, J., M. HER, and G. M. PHILLIPS (2006): "To Sin or Not to Sin? Now That's the Question," Journal of Asset Management, 6, 406-417.

COCHRANE, J. H. (2005): Asset Pricing. Princeton University Press Princeton.

CONRAD, J., M. COOPER, and G. KAUL (2003): "Value Versus Glamour," The Journal of Finance, 58, 1969-1996.

DURAND, R. B., S. KOH, and P. L. TAN (2013): "The Price of Sin in the Pacific-Basin," Pacific-Basin Finance Journal, 21, 899-913.

ERRUNZA, V., and E. LOSQ (1985): "International Asset Pricing under Mild Segmentation - Theory and Test," Journal of Finance, 40, 105-124.

FABOZZI, F. J., K. C. MA, and B. J. OLIPHANT (2008): "Sin Stock Returns," Journal of Portfolio Management, 35, 82-+.

FAMA, E. F., and J. D. MACBETH (1973): "Risk, Return and Equilibrium - Empirical Tests," The Journal of Political Economy, 81, 607.

FANG, L., and J. PERESS (2009): "Media Coverage and the Cross-Section of Stock Returns," Journal of Finance, 64, 2023-2052.

HARVEY, C., Y. LIU, and H. ZHU (2014): "... and the Cross-Section of Expected Returns," Available at SSRN 2249314.

HONG, H., and M. KACPERCZYK (2009): "The Price of Sin: The Effects of Social Norms on Markets," Journal of Financial Economics, 93, 15-36. 
HONG, H., T. LIM, and J. C. STEIN (2000): "Bad News Travels Slowly: Size, Analyst Coverage, and the Profitability of Momentum Strategies," Journal of Finance, 55, 265-295.

JAGANNATHAN, R., and Z. Y. WANG (1996): "The Conditional CAPM and the Cross-Section of Expected Returns," Journal of Finance, 51, 3-53.

- (1998): "An Asymptotic Theory for Estimating Beta-Pricing Models Using Cross-Sectional Regression," Journal of Finance, 53, 1285-1309.

KIM, I., and M. VENKATACHALAM (2011): "Are Sin Stocks Paying the Price for Accounting Sins?," Journal of Accounting, Auditing \& Finance, 26, 415-442.

LEMIEUX, P. (2003): "Does Vice Pay?," National Post.

LEVENTIS, S., I. HASAN, and E. DEDOULIS (2013): "The Cost of Sin: The Effect of Social Norms on Audit Pricing," International Review of Financial Analysis, 29, 152-165.

LEWELLEN, J., S. NAGEL, and J. SHANKEN (2010): "A Skeptical Appraisal of Asset Pricing Tests," Journal of Financial Economics, 96, 175-194.

LISTON, D. P., and G. SOYDEMIR (2010): "Faith-Based and Sin Portfolios: An Empirical Inquiry into Norm-Neglect Vs Norm-Conforming Investor Behavior," Managerial Finance, 36, 876-885.

LIU, Y., H. LU, and K. VEENSTRA (2014): "Is Sin Always a Sin? The Interaction Effect of Social Norms and Financial Incentives on Market Participants' Behavior," Accounting, Organizations and Society, 39, 289-307.

LO, A. W., and A. C. MACKINLAY (1990): "Data-Snooping Biases in Tests of Financial Asset PricingModels," Review of Financial Studies, 3, 431-467.

LOBE, S., and C. WALKSHÄUSL (2008): "Vice Vs. Virtue Investing around the World," Virtue Investing Around the World (May 9, 2011).

MERTON, R. C. (1987): "A Simple-Model of Capital-Market Equilibrium with Incomplete Information," Journal of Finance, 42, 483-510.

PASTOR, L., and R. F. STAMBAUGH (2003): "Liquidity Risk and Expected Stock Returns," Journal of Political Economy, 111, 642-685.

RENNEBOOG, L., J. TER HORST, and C. D. ZHANG (2008): "Socially Responsible Investing: Institutional Aspects, Performance, and Investor Behavior," Journal of Banking \& Finance, 32, $1723-1742$.

- (2011): "Is Ethical Money Financially Smart? Nonfinancial Attributes and Money Flows of Socially Responsible Investing Funds," Journal of Financial Intermediation, 20, 562-588.

SALABER, J. (2007): "The Determinants of Sin Stock Returns: Evidence on the European Market."

— (2009): "Sin Stock Returns over the Business Cycle," Available at SSRN 1443188.

SHANKEN, J. (1992): "On the Estimation of Beta-Pricing Models," Review of Financial Studies, 5, 1-33. 
SÖDERSTRÖM , T. (1994): Discrete-time Stochastic Systems: Estimation and Control. Prentice-Hall, New York.

STATMAN, M., and D. GLUSHKOV (2009): "The Wages of Social Responsibility," Financial Analysts Journal, 65, 33-46.

TEOH, S. H., I. WELCH, and C. P. WAZZAN (1999): "The Effect of Socially Activist Investment Policies on the Financial Markets: Evidence from the South African Boycott," Journal of Business, 72, 35-89.

VISALTANACHOTI, N., Q. ZHENG, and L. ZOU (2011): "The Performance of Sin Stocks in China," Journal of International Finance Studies, 11.

WAXLER, C. (2004): Stocking up on Sin: How to Crush the Market with Vice-Based Investing. Wiley. 


\section{Table 1 Socially Responsible Investing Trends in the United States}

This table shows for the U.S. the year-by-year amounts of assets (in units of $\$ 1$ trillion) under professional management, invested in Socially Responsible Investing funds, and subject to screens.

TRNT Assets: Thomson Reuters Nelson Tracked Assets. E.g. \$16.30 in 1999 means that according to the 1999 Thomson Reuters Nelson' Directory of Investment Managers, there were \$16.3 trillion in investment assets under professional management in the U.S.

SRI Assets: Socially Responsible Investing Assets. E.g. \$2.16 in 1999 means that among the \$16.3 trillion assets under professional management (including pension funds, mutual fund families, foundations, religious organizations and community development financial institutions), \$2.16 trillion assets were considered as following Socially Responsible Investing policy.

Screened Assets: E.g. \$1.50 in 1999 means that of the \$2.16 trillion SRI assets, \$1.5 trillion assets employed at least one negative screen restricting investment in certain industries.

\begin{tabular}{lccccccccc}
\hline \hline & $\mathbf{1 9 9 5}$ & $\mathbf{1 9 9 7}$ & $\mathbf{1 9 9 9}$ & $\mathbf{2 0 0 1}$ & $\mathbf{2 0 0 3}$ & $\mathbf{2 0 0 5}$ & $\mathbf{2 0 0 7}$ & $\mathbf{2 0 1 0}$ & $\mathbf{2 0 1 2}$ \\
\hline Screened Assets & $\$ 0.16$ & $\$ 0.53$ & $\$ 1.50$ & $\$ 2.01$ & $\$ 2.14$ & $\$ 1.69$ & $\$ 2.10$ & $\$ 2.51$ & $\$ 3.31$ \\
SRI Assets & $\$ 0.64$ & $\$ 1.19$ & $\$ 2.16$ & $\$ 2.34$ & $\$ 2.18$ & $\$ 2.29$ & $\$ 2.71$ & $\$ 3.07$ & $\$ 3.74$ \\
TRNT Assets & $\$ 7.00$ & $\$ 13.70$ & $\$ 16.30$ & $\$ 19.90$ & $\$ 19.20$ & $\$ 24.40$ & $\$ 25.10$ & $\$ 25.20$ & $\$ 33.30$ \\
\hline
\end{tabular}




\section{Table 2 Profile of Boycotted Stocks}

This table reports the number of firms by year and average market capitalization (in units of $\$ 1$ million) of the boycotted stocks subject to the most prevalent screens used by SRI portfolios. The definitions of Tobacco, Alcohol, Coal, Fossil (Coal, Oil, and Gas), and Weapons are based on the Fama-French SIC based classification scheme. Stocks with SIC codes of 2100-2199 belong to the tobacco industry, those with SIC codes of 2080-2085 are in the alcohol industry, and those with SIC codes of 1200-1299 are in the coal industry. Stocks with SIC codes of 1300-1389 are in the oil and gas industry, and those with SIC codes of 3769-3769, 3795, and 3480-3489 are in the weapons industry. Gaming stocks are identified following HK (2009)'s NAICS codes: 7132, 71312, 713210, 71329, 713290, 72112, and 721120.

\begin{tabular}{|c|c|c|c|c|c|c|c|c|c|c|c|c|}
\hline \multicolumn{7}{|c|}{ Number of Firms } & \multicolumn{6}{|c|}{ Average Market Capitalization (\$ Million) } \\
\hline Year & Tobacco & Alcohol & Coal & Fossil & Weapons & Gaming & Tobacco & Alcohol & Coal & Fossil & Weapons & Gaming \\
\hline 1963 & 10 & 9 & 3 & 22 & 4 & $\mathrm{n} / \mathrm{a}$ & 316 & 148 & 69 & 157 & 220 & $\mathrm{n} / \mathrm{a}$ \\
\hline 1964 & 12 & 9 & 4 & 26 & 4 & $\mathrm{n} / \mathrm{a}$ & 335 & 158 & 158 & 172 & 177 & $\mathrm{n} / \mathrm{a}$ \\
\hline 1965 & 12 & 10 & 4 & 30 & 4 & $\mathrm{n} / \mathrm{a}$ & 342 & 184 & 160 & 180 & 194 & $\mathrm{n} / \mathrm{a}$ \\
\hline 1966 & 13 & 10 & 5 & 51 & 4 & $\mathrm{n} / \mathrm{a}$ & 279 & 151 & 127 & 122 & 186 & $\mathrm{n} / \mathrm{a}$ \\
\hline 1967 & 10 & 12 & 4 & 52 & 4 & $\mathrm{n} / \mathrm{a}$ & 348 & 192 & 119 & 162 & 202 & $\mathrm{n} / \mathrm{a}$ \\
\hline 1968 & 10 & 12 & 4 & 54 & 4 & $\mathrm{n} / \mathrm{a}$ & 379 & 229 & 160 & 223 & 209 & $\mathrm{n} / \mathrm{a}$ \\
\hline 1969 & 10 & 14 & 4 & 59 & 4 & $\mathrm{n} / \mathrm{a}$ & 388 & 223 & 152 & 219 & 197 & $\mathrm{n} / \mathrm{a}$ \\
\hline 1970 & 10 & 14 & 4 & 62 & 4 & $\mathrm{n} / \mathrm{a}$ & 415 & 210 & 202 & 173 & 133 & $\mathrm{n} / \mathrm{a}$ \\
\hline 1971 & 11 & 13 & 5 & 64 & 4 & $\mathrm{n} / \mathrm{a}$ & 583 & 234 & 224 & 231 & 186 & $\mathrm{n} / \mathrm{a}$ \\
\hline 1972 & 11 & 13 & 5 & 69 & 4 & $\mathrm{n} / \mathrm{a}$ & 705 & 335 & 170 & 239 & 176 & $\mathrm{n} / \mathrm{a}$ \\
\hline 1973 & 11 & 22 & 8 & 100 & 7 & $\mathrm{n} / \mathrm{a}$ & 632 & 241 & 94 & 173 & 84 & $\mathrm{n} / \mathrm{a}$ \\
\hline 1974 & 11 & 21 & 10 & 106 & 8 & $\mathrm{n} / \mathrm{a}$ & 545 & 171 & 105 & 141 & 69 & $\mathrm{n} / \mathrm{a}$ \\
\hline 1975 & 10 & 20 & 10 & 112 & 8 & $\mathrm{n} / \mathrm{a}$ & 708 & 179 & 194 & 152 & 72 & $\mathrm{n} / \mathrm{a}$ \\
\hline 1976 & 10 & 20 & 11 & 123 & 7 & $\mathrm{n} / \mathrm{a}$ & 829 & 219 & 238 & 163 & 113 & $\mathrm{n} / \mathrm{a}$ \\
\hline 1977 & 10 & 19 & 11 & 122 & 8 & $\mathrm{n} / \mathrm{a}$ & 873 & 167 & 207 & 184 & 118 & $\mathrm{n} / \mathrm{a}$ \\
\hline 1978 & 10 & 19 & 9 & 127 & 8 & $\mathrm{n} / \mathrm{a}$ & 925 & 170 & 209 & 186 & 298 & $\mathrm{n} / \mathrm{a}$ \\
\hline 1979 & 10 & 19 & 8 & 158 & 10 & $\mathrm{n} / \mathrm{a}$ & 1022 & 212 & 263 & 230 & 368 & $\mathrm{n} / \mathrm{a}$ \\
\hline 1980 & 9 & 19 & 8 & 212 & 9 & $\mathrm{n} / \mathrm{a}$ & 1355 & 251 & 357 & 365 & 464 & $\mathrm{n} / \mathrm{a}$ \\
\hline 1981 & 9 & 17 & 8 & 302 & 9 & $\mathrm{n} / \mathrm{a}$ & 1651 & 310 & 322 & 260 & 507 & $\mathrm{n} / \mathrm{a}$ \\
\hline 1982 & 8 & 17 & 8 & 334 & 8 & $\mathrm{n} / \mathrm{a}$ & 2008 & 378 & 217 & 133 & 438 & $\mathrm{n} / \mathrm{a}$ \\
\hline 1983 & 9 & 18 & 8 & 331 & 8 & $\mathrm{n} / \mathrm{a}$ & 2330 & 448 & 239 & 166 & 630 & $\mathrm{n} / \mathrm{a}$ \\
\hline 1984 & 8 & 18 & 10 & 319 & 9 & $\mathrm{n} / \mathrm{a}$ & 2866 & 371 & 177 & 158 & 576 & $\mathrm{n} / \mathrm{a}$ \\
\hline 1985 & 6 & 18 & 11 & 301 & 8 & 8 & 4374 & 465 & 179 & 186 & 671 & 113 \\
\hline 1986 & 7 & 17 & 13 & 284 & 9 & 7 & 4732 & 730 & 150 & 191 & 703 & 199 \\
\hline 1987 & 6 & 16 & 13 & 252 & 8 & 7 & 5797 & 951 & 153 & 282 & 769 & 249 \\
\hline 1988 & 7 & 17 & 13 & 235 & 8 & 8 & 4962 & 895 & 191 & 280 & 863 & 226 \\
\hline 1989 & 7 & 17 & 13 & 228 & 8 & 8 & 7360 & 894 & 277 & 382 & 870 & 302 \\
\hline 1990 & 7 & 17 & 9 & 237 & 8 & 12 & 7380 & 892 & 229 & 445 & 799 & 296 \\
\hline 1991 & 7 & 16 & 9 & 233 & 10 & 10 & 12066 & 1233 & 214 & 404 & 860 & 389 \\
\hline 1992 & 6 & 16 & 10 & 230 & 11 & 11 & 15760 & 1291 & 195 & 406 & 854 & 520 \\
\hline 1993 & 6 & 18 & 10 & 248 & 11 & 25 & 11328 & 1075 & 230 & 461 & 963 & 665 \\
\hline 1994 & 6 & 18 & 11 & 243 & 10 & 34 & 11237 & 1035 & 264 & 460 & 656 & 441 \\
\hline 1995 & 6 & 22 & 11 & 239 & 11 & 35 & 13999 & 1122 & 262 & 521 & 1734 & 455 \\
\hline 1996 & 7 & 23 & 11 & 237 & 12 & 37 & 16064 & 1128 & 646 & 742 & 2386 & 494 \\
\hline 1997 & 9 & 26 & 9 & 226 & 12 & 37 & 16418 & 1302 & 397 & 993 & 2666 & 426 \\
\hline 1998 & 8 & 26 & 5 & 197 & 12 & 31 & 15933 & 1554 & 507 & 735 & 3007 & 391 \\
\hline 1999 & 6 & 26 & 5 & 162 & 10 & 26 & 16047 & 2046 & 351 & 864 & 1925 & 672 \\
\hline 2000 & 4 & 24 & 6 & 155 & 6 & 20 & 3432 & 2108 & 289 & 1156 & 2555 & 851 \\
\hline 2001 & 6 & 19 & 7 & 163 & 8 & 22 & 23805 & 2518 & 857 & 1260 & 3197 & 822 \\
\hline 2002 & 5 & 17 & 5 & 133 & 9 & 22 & 22347 & 3233 & 1051 & 1344 & 3645 & 1255 \\
\hline 2003 & 5 & 17 & 5 & 125 & 9 & 22 & 18913 & 3080 & 1106 & 1629 & 2790 & 1357 \\
\hline 2004 & 5 & 14 & 5 & 124 & 10 & 19 & 24576 & 4030 & 2045 & 1907 & 3213 & 1889 \\
\hline 2005 & 5 & 13 & 10 & 136 & 10 & 20 & 32670 & 3969 & 2682 & 2726 & 3724 & 3188 \\
\hline 2006 & 5 & 12 & 12 & 157 & 10 & 18 & 20152 & 4078 & 3211 & 2930 & 4936 & 4013 \\
\hline 2007 & 7 & 13 & 11 & 162 & 10 & 17 & 20238 & 4141 & 3240 & 3131 & 5763 & 6444 \\
\hline 2008 & 7 & 11 & 11 & 157 & 10 & 16 & 26950 & 1277 & 4258 & 3705 & 5234 & 3113 \\
\hline 2009 & 7 & 11 & 11 & 153 & 10 & 14 & 22441 & 1076 & 2464 & 2731 & 4013 & 1628 \\
\hline 2010 & 7 & 12 & 10 & 139 & 9 & 14 & 26614 & 995 & 3831 & 3468 & 4596 & 3127 \\
\hline 2011 & 7 & 13 & 8 & 145 & 8 & 14 & 34665 & 1098 & 4976 & 4269 & 5763 & 4475 \\
\hline 2012 & 6 & 13 & 9 & 140 & 6 & 15 & 42626 & 1879 & 2710 & 3658 & 3591 & 4223 \\
\hline Average & 8 & 17 & 8 & 166 & 8 & 13 & 10054 & 1106 & 823 & 909 & 1567 & 984 \\
\hline
\end{tabular}




\section{Table 3 Investment Screens in Previous Literature}

This table provides a survey of the previous academic literature regarding the investment screens applied to identify sin firms. NAICS stands for the North American Industry Classification System, SIC stands for the Standard Industry Classification Code, Permno is a stock identifier. HK is Hong and Kacperczyk (2009). Other papers following the HK criteria are Liston and Soydemir (2010), Salaber (2007, 2009), Chong, Her and Phillips (2006), Liu, Lu, and Veenstra (2014), and Visaltanachoti, Zheng, and Zou (2011). KV is Kim and Venkatachalam (2011). RHZ is Renneboog, Horst, and Zhang (2008, 2011). RHZ's ethical negative screens include animal testing, abortion, genetic engineering, non-marital insurance. RHZ's social negative screens cover workplace diversity, human rights, and labor standards. RHZ's environmental negative screens include firms that: have low environmental standards, contribute to global warming, and/or operate nuclear power plants. FMO is Fabozzi, Ma, and Oliphant (2008). LW is Lobe and Walkshäusl (2011). SRI \% refers to the percentage of SRI funds employing the particular screen as reported in the Social Investment Forum for 1999.

\begin{tabular}{|c|c|c|c|c|c|c|}
\hline Screen & SRI \% & HK & $\mathrm{KV}$ & RHZ & FMO & LW \\
\hline Tobacco & 96 & SIC & SIC & $\mathrm{Y}$ & $\mathrm{Y}$ & $\mathrm{Y}$ \\
\hline Alcohol & 83 & SIC & SIC & $\mathrm{Y}$ & $\mathrm{Y}$ & $\mathrm{Y}$ \\
\hline Gaming & 86 & NAICS & NAICS & Y & $\mathrm{Y}$ & $\mathrm{Y}$ \\
\hline Weapons & 81 & $(\mathrm{SIC})^{*}$ & & $\mathrm{Y}$ & $\mathrm{Y}$ & Y \\
\hline Pornography & & & PERMNO & $\mathrm{Y}$ & $\mathrm{Y}$ & $\mathrm{Y}$ \\
\hline Ethical & $23 * *$ & & & $\mathrm{Y}$ & $\mathrm{Y}$ & \\
\hline Social & & & & $\mathrm{Y}$ & & \\
\hline Environmental & 79 & & & Y & & $\mathrm{Y}$ \\
\hline Region & World & US & US & World & World & World \\
\hline
\end{tabular}




\section{Table $4 \quad$ Factor Summary Statistics}

This table provides summary statistics for the risk factors used in the model comparisons. We consider both the recent period, 1999-2012, and the full sample period, 1963-2012. The meanings of the factor abbreviations are described in the label column. The italic numbers are the $p$-values in the correlation table.

Panel A. Period 1999-2012

\begin{tabular}{l|cccccl}
\hline \hline Factor & N & Mean & Std. & Min & Max & \\
\hline MKT & 168 & 0.220 & 4.730 & -17.230 & 11.340 & Market Excess Return \% \\
SMB & 168 & 0.471 & 3.731 & -16.390 & 22.020 & Small-Big Return \% \\
HML & 168 & 0.321 & 3.611 & -12.680 & 13.870 & High-Low Return \% \\
UMD & 168 & 0.306 & 6.133 & -34.720 & 18.390 & Momentum Factor \% \\
BCTn & 168 & 0.766 & 5.010 & -11.772 & 19.433 & Market Orthogonalized Boycott Factor \% [Narrow Screen] \\
BCTb & 168 & 1.210 & 4.821 & -11.781 & 16.220 & Market Orthogonalized Boycott Factor \% [Broad Screen] \\
\hline
\end{tabular}

\begin{tabular}{l|llllll}
\hline Corr. & MKT & SMB & HML & UMD & BCTn & BCTb \\
\hline MKT & 1.000 & 0.290 & -0.166 & -0.337 & 0.003 & 0.013 \\
& & 0.000 & 0.031 & 0.000 & 0.970 & 0.863 \\
SMB & & 1.000 & -0.363 & 0.123 & -0.225 & -0.141 \\
& & & 0.000 & 0.111 & 0.003 & 0.068 \\
HML & & & 1.000 & -0.156 & 0.407 & 0.399 \\
& & & & 0.044 & 0.000 & 0.000 \\
UMD & & & & 1.000 & -0.064 & 0.005 \\
& & & & & 0.411 & 0.952 \\
BCTn & & & & & 1.000 & 0.619 \\
& & & & & & 0.000 \\
BCTb & & & & & & 1.000
\end{tabular}

Panel B. Period 1963-2012

\begin{tabular}{l|cccccl}
\hline \hline Factor & N & Mean & Std. & Min & Max & Label \\
\hline MKT & 600 & 0.469 & 4.498 & -23.240 & 16.100 & Market Excess Return \% \\
SMB & 600 & 0.250 & 3.120 & -16.390 & 22.020 & Small-Big Return \% \\
HML & 600 & 0.394 & 2.891 & -12.680 & 13.870 & High-Low Return \% \\
UMD & 600 & 0.702 & 4.279 & -34.720 & 18.390 & Momentum Factor \% \\
BCTn & 600 & 0.323 & 3.942 & -15.506 & 17.926 & Market Orthogonalized Boycott Factor \% [Narrow Screen] \\
BCTb & 600 & 0.382 & 3.423 & -11.696 & 16.088 & Market Orthogonalized Boycott Factor \% [Broad Screen] \\
\hline
\end{tabular}

\begin{tabular}{l|llllll}
\hline Corr. & MKT & SMB & HML & UMD & BCTn & BCTb \\
\hline MKT & 1.000 & 0.309 & -0.301 & -0.128 & 0.005 & 0.005 \\
& & & 0.000 & 0.002 & 0.913 & 0.899 \\
SMB & & & -0.227 & -0.009 & -0.146 & -0.032 \\
& & & 0.000 & 0.833 & 0.000 & 0.428 \\
HML & & & 1.000 & -0.153 & 0.152 & 0.168 \\
& & & & 0.000 & 0.000 & 0.000 \\
UMD & & & & 1.000 & -0.017 & 0.056 \\
& & & & & 0.681 & 0.169 \\
BCTn & & & & & 1.000 & 0.503 \\
& & & & & & 0.000 \\
BCTb & & & & & & 1.000
\end{tabular}




\section{Table 5 Model Comparison for the Narrow Boycott Factor}

The table reports the factor risk premiums estimated from cross-sectional regressions of the CAPM, Boycott-CAPM, FF3, Boycott-FF3, FF4, and Boycott-FF4 models for FF30 and FF48 industry test portfolios, using the narrow Boycott factor measure, based on the tobacco, alcohol, and coal industries. The t-statistics are based on the Black-Jensen-Scholes cross-sectional regression slopes, and the GMM tstatistics (with 12 monthly lags). The adjusted R-square is from a single cross-section regression. The full sample period for the FF48 test portfolios is shortened due to availability of the Health portfolio.

\begin{tabular}{|c|c|c|c|c|c|c|c|}
\hline \multicolumn{8}{|c|}{ Panel A. 1999-2012 } \\
\hline FF30 & Const & MKT & SMB & HML & UMD & BCT & $\mathrm{R}^{2}$ \\
\hline $\mathrm{RP}$ & 0.415 & 0.111 & & & & & -0.026 \\
\hline$B J S-t$ & 1.315 & 0.236 & & & & & \\
\hline$G M M-t$ & 1.157 & 0.220 & & & & & \\
\hline RP & -0.286 & 0.594 & & & & 1.332 & 0.481 \\
\hline$B J S-t$ & -0.765 & 1.156 & & & & 2.287 & \\
\hline$G M M-t$ & -0.615 & 0.940 & & & & 2.063 & \\
\hline RP & 0.584 & -0.173 & 0.711 & 0.234 & & & 0.063 \\
\hline$B J S-t$ & 1.657 & -0.345 & 1.366 & 0.714 & & & \\
\hline$G M M-t$ & 1.778 & -0.337 & 1.769 & 0.660 & & & \\
\hline $\mathrm{RP}$ & -0.211 & 0.552 & 0.027 & 0.198 & & 1.327 & 0.455 \\
\hline$B J S-t$ & -0.574 & 1.066 & 0.059 & 0.600 & & 2.197 & \\
\hline$G M M-t$ & -0.48 & 0.883 & 0.072 & 0.516 & & 2.207 & \\
\hline $\mathrm{RP}$ & 0.301 & 0.159 & 0.583 & 0.356 & 1.761 & & 0.420 \\
\hline$B J S-t$ & 0.845 & 0.306 & 1.196 & 1.056 & 1.574 & & \\
\hline$G M M-t$ & 0.731 & 0.26 & 1.419 & 0.95 & 1.895 & & \\
\hline RP & -0.148 & 0.542 & 0.155 & 0.287 & 0.855 & 1.045 & 0.557 \\
\hline$B J S-t$ & -0.438 & 1.054 & 0.332 & 0.841 & 0.829 & 2.088 & \\
\hline$G M M-t$ & -0.385 & 0.876 & 0.369 & 0.745 & 0.848 & 2.294 & \\
\hline
\end{tabular}

\begin{tabular}{|c|c|c|c|c|c|c|c|}
\hline \multicolumn{8}{|c|}{ Panel B. 1999-2012 } \\
\hline FF48 & Const & MKT & SMB & HML & UMD & BCT & $\mathrm{R}^{2}$ \\
\hline $\mathrm{RP}$ & 0.479 & 0.068 & & & & & -0.017 \\
\hline$B J S-t$ & 1.523 & 0.150 & & & & & \\
\hline$G M M-t$ & 1.305 & 0.136 & & & & & \\
\hline $\mathrm{RP}$ & -0.127 & 0.498 & & & & 1.231 & 0.400 \\
\hline$B J S-t$ & -0.425 & 1.063 & & & & 2.199 & \\
\hline$G M M-t$ & -0.342 & 0.870 & & & & 1.903 & \\
\hline $\mathrm{RP}$ & 0.372 & 0.061 & 0.221 & 0.213 & & & 0.035 \\
\hline$B J S-t$ & 1.382 & 0.137 & 0.592 & 0.648 & & & \\
\hline$G M M-t$ & 1.466 & 0.124 & 0.841 & 0.571 & & & \\
\hline $\mathrm{RP}$ & -0.039 & 0.426 & 0.126 & 0.173 & & 1.270 & 0.415 \\
\hline$B J S-t$ & -0.14 & 0.933 & 0.343 & 0.524 & & 2.294 & \\
\hline$G M M-t$ & -0.112 & 0.746 & 0.459 & 0.452 & & 2.267 & \\
\hline $\mathrm{RP}$ & 0.166 & 0.314 & 0.29 & 0.3 & 1.451 & & 0.349 \\
\hline$B J S-t$ & 0.598 & 0.678 & 0.757 & 0.905 & 1.479 & & \\
\hline$G M M-t$ & 0.519 & 0.559 & 0.913 & 0.759 & 1.720 & & \\
\hline $\mathrm{RP}$ & -0.064 & 0.493 & 0.195 & 0.239 & 0.822 & 1.045 & 0.512 \\
\hline$B J S-t$ & -0.223 & 1.047 & 0.516 & 0.718 & 0.904 & 2.179 & \\
\hline$G M M-t$ & -0.178 & 0.813 & 0.622 & 0.612 & 0.964 & 2.290 & \\
\hline
\end{tabular}

\begin{tabular}{lccccccc}
\hline \hline \multicolumn{7}{c}{ Panel C. 1999-2012 } \\
\hline FF55 & Const & MKT & SMB & HML & UMD & BCT & R $^{2}$ \\
\hline RP & 0.437 & 0.135 & & & & & -0.007 \\
BJS- $t$ & 1.226 & 0.273 & & & & & \\
$G M M-t$ & 1.071 & 0.259 & & & & & \\
RP & -0.142 & 0.590 & & & & 0.998 & 0.254 \\
BJS- $t$ & -0.414 & 1.158 & & & & 1.716 & \\
$G M M-t$ & -0.352 & 0.972 & & & & 1.512 & \\
& & & & & & & \\
RP & 0.425 & -0.062 & 0.379 & 0.322 & & & 0.228 \\
$B J S-t$ & 1.455 & -0.132 & 1.28 & 1.071 & & & \\
$G M M-t$ & 1.487 & -0.125 & 1.58 & 0.937 & & & \\
& & & & & & & \\
RP & 0.037 & 0.283 & 0.389 & 0.257 & & 1.136 & 0.488 \\
$B J S-t$ & 0.109 & 0.566 & 1.312 & 0.857 & & 1.968 & \\
$G M M-t$ & 0.094 & 0.468 & 1.606 & 0.752 & & 1.957 & \\
RP & 0.178 & 0.245 & 0.36 & 0.376 & 1.671 & & 0.502 \\
$B J S-t$ & 0.524 & 0.47 & 1.216 & 1.233 & 1.728 & & \\
$G M M-t$ & 0.43 & 0.381 & 1.499 & 1.117 & 2.062 & & \\
RP & -0.015 & 0.391 & 0.373 & 0.316 & 1.135 & 0.909 & 0.597 \\
$B J S-t$ & -0.041 & 0.732 & 1.256 & 1.043 & 1.322 & 1.827 & \\
$G M M-t$ & -0.033 & 0.568 & 1.551 & 0.952 & 1.344 & 1.909 & \\
\hline & & & & & & & \\
\hline
\end{tabular}




\begin{tabular}{llllllll}
\hline \hline \multicolumn{7}{c}{ Panel D. 1963-2012 } \\
\hline FF30 & Const & MKT & SMB & HML & UMD & BCT & $\mathrm{R}^{2}$ \\
\hline RP & 0.618 & -0.025 & & & & & -0.035 \\
$B J S-t$ & 2.657 & -0.084 & & & & & \\
$G M M-t$ & 2.637 & -0.080 & & & & & \\
& & & & & & & \\
RP & 0.164 & 0.360 & & & & 0.535 & 0.480 \\
$B J S-t$ & 0.695 & 1.183 & & & & 2.628 & \\
$G M M-t$ & 0.636 & 1.095 & & & & 2.402 & \\
& & & & & & & \\
RP & 0.707 & -0.104 & 0.051 & -0.064 & & & -0.089 \\
$B J S-t$ & 2.521 & -0.314 & 0.277 & -0.406 & & & \\
$G M M-t$ & 2.570 & -0.319 & 0.261 & -0.353 & & & \\
& & & & & & & \\
RP & 0.210 & 0.335 & 0.036 & -0.123 & & 0.523 & 0.494 \\
$B J S-t$ & 0.757 & 1.011 & 0.192 & -0.784 & & 2.511 & \\
$G M M-t$ & 0.750 & 1.044 & 0.181 & -0.698 & & 2.341 & \\
& & & & & & & \\
RP & 0.584 & 0.027 & 0.083 & -0.024 & 0.516 & & -0.022 \\
$B J S-t$ & 1.918 & 0.076 & 0.434 & -0.144 & 0.880 & & \\
$G M M-t$ & 1.756 & 0.072 & 0.406 & -0.128 & 0.876 & & \\
RP & 0.178 & 0.374 & 0.051 & -0.103 & 0.201 & 0.507 & 0.494 \\
$B J S-t$ & 0.592 & 1.046 & 0.262 & -0.607 & 0.342 & 2.509 & \\
$G M M-t$ & 0.539 & 0.995 & 0.248 & -0.55 & 0.328 & 2.376 & \\
\hline
\end{tabular}

\begin{tabular}{lrrrrrrr}
\hline \hline \multicolumn{7}{c}{ Panel E. 1969-2012 } \\
\hline FF48 & Const & MKT & SMB & HML & UMD & BCT & $\mathrm{R}^{2}$ \\
\hline RP & 0.767 & -0.214 & & & & & 0.035 \\
$B J S-t$ & 3.077 & -0.677 & & & & & \\
$G M M-t$ & 3.176 & -0.641 & & & & & \\
& & & & & & & \\
RP & 0.399 & 0.098 & & & & 0.475 & 0.214 \\
$B J S-t$ & 1.539 & 0.298 & & & & 1.986 & \\
$G M M-t$ & 1.486 & 0.277 & & & & 1.746 & \\
& & & & & & & \\
RP & 0.580 & 0.014 & -0.258 & -0.014 & & & 0.096 \\
$B J S-t$ & 1.938 & 0.038 & -1.339 & -0.083 & & & \\
$G M M-t$ & 2.076 & 0.039 & -1.28 & -0.071 & & & \\
& & & & & & & \\
RP & 0.246 & 0.298 & -0.234 & -0.077 & & 0.524 & 0.288 \\
$B J S-t$ & 0.790 & 0.809 & -1.222 & -0.448 & & 2.166 & \\
$G M M-t$ & 0.834 & 0.83 & -1.153 & -0.396 & & 1.934 & \\
& & & & & & & \\
RP & 0.469 & 0.135 & -0.255 & -0.000 & 0.343 & & 0.106 \\
$B J S-t$ & 1.557 & 0.371 & -1.314 & -0.002 & 0.586 & & \\
$G M M-t$ & 1.473 & 0.356 & -1.262 & -0.002 & 0.566 & & \\
RP & 0.206 & 0.345 & -0.233 & -0.068 & 0.142 & 0.514 & 0.278 \\
$B J S-t$ & 0.655 & 0.921 & -1.215 & -0.384 & 0.238 & 2.111 & \\
$G M M-t$ & 0.612 & 0.874 & -1.151 & -0.342 & 0.224 & 1.907 & \\
\hline
\end{tabular}

\begin{tabular}{|c|c|c|c|c|c|c|c|}
\hline \multicolumn{8}{|c|}{ Panel F. 1963-2012 } \\
\hline FF55 & Const & MKT & SMB & HML & UMD & $\mathrm{BCT}$ & $\mathrm{R}^{2}$ \\
\hline $\mathrm{RP}$ & 0.760 & -0.111 & & & & & -0.008 \\
\hline$B J S-t$ & 3.105 & -0.359 & & & & & \\
\hline$G M M-t$ & 2.959 & -0.332 & & & & & \\
\hline RP & 0.456 & 0.159 & & & & 0.382 & 0.069 \\
\hline$B J S-t$ & 1.928 & 0.521 & & & & 1.903 & \\
\hline$G M M-t$ & 1.768 & 0.482 & & & & 1.759 & \\
\hline $\mathrm{RP}$ & 0.935 & -0.395 & 0.171 & 0.258 & & & 0.313 \\
\hline$B J S-t$ & 3.974 & -1.328 & 1.307 & 2.066 & & & \\
\hline$G M M-t$ & 4.149 & -1.341 & 1.253 & 1.801 & & & \\
\hline $\mathrm{RP}$ & 0.632 & -0.136 & 0.205 & 0.244 & & 0.426 & 0.432 \\
\hline$B J S-t$ & 2.706 & -0.455 & 1.574 & 1.955 & & 2.120 & \\
\hline$G M M-t$ & 2.617 & -0.447 & 1.513 & 1.715 & & 1.961 & \\
\hline RP & 0.691 & -0.135 & 0.172 & 0.278 & 0.707 & & 0.380 \\
\hline$B J S-t$ & 2.392 & -0.386 & 1.316 & 2.21 & 1.355 & & \\
\hline$G M M-t$ & 2.117 & -0.35 & 1.263 & 1.973 & 1.314 & & \\
\hline $\mathrm{RP}$ & 0.463 & 0.05 & 0.203 & 0.261 & 0.544 & 0.412 & 0.473 \\
\hline$B J S-t$ & 1.577 & 0.142 & 1.555 & 2.085 & 1.061 & 2.078 & \\
\hline$G M M-t$ & 1.358 & 0.126 & 1.494 & 1.867 & 1.005 & 1.979 & \\
\hline
\end{tabular}




\section{Table 6 Market and Boycott Factor Loadings}

Panel A. This table presents the factor loadings obtained from the first-pass regressions for the two-factor boycott-augmented CAPM, using the narrow boycott factor measure (tobacco, alcohol, and coal industries). The industry order is determined by the boycott factor loadings (BCT Beta) from highest to lowest.

\begin{tabular}{|c|c|c|c|c|c|}
\hline \multicolumn{6}{|c|}{ FF30 Factor Loadings } \\
\hline \multicolumn{3}{|c|}{ 1999-2012 } & \multicolumn{3}{|c|}{$1963-2012$} \\
\hline Industry & MKT Beta & BCT Beta & Industry & MKT Beta & BCT Beta \\
\hline Smoke & 0.446 & 1.204 & Smoke & 0.674 & 1.187 \\
\hline Coal & 1.310 & 0.635 & Coal & 1.161 & 0.402 \\
\hline Util & 0.406 & 0.393 & Beer & 0.761 & 0.400 \\
\hline Mines & 1.000 & 0.381 & Food & 0.713 & 0.354 \\
\hline Beer & 0.322 & 0.333 & Util & 0.530 & 0.223 \\
\hline Oil & 0.754 & 0.305 & Hlth & 0.832 & 0.212 \\
\hline Food & 0.403 & 0.299 & Hshld & 0.820 & 0.181 \\
\hline Carry & 0.962 & 0.254 & Meals & 1.074 & 0.150 \\
\hline Whlsl & 0.818 & 0.225 & Whlsl & 1.074 & 0.119 \\
\hline Cnstr & 1.128 & 0.216 & Cnstr & 1.186 & 0.099 \\
\hline Txtls & 1.340 & 0.205 & Paper & 0.950 & 0.086 \\
\hline Hshld & 0.477 & 0.185 & Mines & 0.953 & 0.082 \\
\hline Chems & 1.080 & 0.177 & Fin & 1.068 & 0.081 \\
\hline Hlth & 0.524 & 0.171 & Carry & 1.118 & 0.074 \\
\hline Paper & 0.862 & 0.157 & Chems & 1.040 & 0.066 \\
\hline Fin & 1.030 & 0.156 & Other & 1.084 & 0.064 \\
\hline Meals & 0.670 & 0.155 & Oil & 0.790 & 0.059 \\
\hline Trans & 0.885 & 0.112 & Clths & 1.130 & 0.055 \\
\hline Other & 0.847 & 0.089 & Txtls & 1.135 & 0.033 \\
\hline Books & 1.038 & 0.086 & Rtail & 0.998 & 0.021 \\
\hline Clths & 1.017 & 0.051 & Books & 1.072 & 0.015 \\
\hline Games & 1.396 & 0.036 & Trans & 1.081 & 0.004 \\
\hline ElcEq & 1.303 & 0.032 & ElcEq & 1.214 & -0.004 \\
\hline Autos & 1.418 & 0.029 & Games & 1.330 & -0.004 \\
\hline FabPr & 1.405 & 0.022 & Telcm & 0.767 & -0.044 \\
\hline Steel & 1.810 & -0.012 & $\mathrm{FabPr}$ & 1.226 & -0.063 \\
\hline Telcm & 1.001 & -0.046 & Autos & 1.138 & -0.080 \\
\hline Rtail & 0.813 & -0.082 & Steel & 1.295 & -0.113 \\
\hline Servs & 1.327 & -0.285 & Servs & 1.325 & -0.153 \\
\hline BusEq & 1.606 & -0.335 & BusEq & 1.286 & -0.269 \\
\hline Mean & 0.980 & 0.172 & & 1.027 & 0.108 \\
\hline Std. & 0.381 & 0.274 & & 0.208 & 0.252 \\
\hline
\end{tabular}

\begin{tabular}{|c|c|c|c|c|c|}
\hline \multicolumn{6}{|c|}{ FF48 Factor Loadings } \\
\hline & $1999-2012$ & & & $1969-2012$ & \\
\hline Industry & MKT Beta & BCT Beta & Industry & MKT Beta & BCT Beta \\
\hline Smoke & 0.446 & 1.204 & Smoke & 0.673 & 1.177 \\
\hline Coal & 1.310 & 0.635 & Coal & 1.182 & 0.413 \\
\hline Util & 0.406 & 0.393 & Beer & 0.755 & 0.402 \\
\hline Gold & 0.332 & 0.374 & Food & 0.677 & 0.372 \\
\hline Ships & 1.070 & 0.374 & Soda & 0.846 & 0.285 \\
\hline Mines & 1.344 & 0.340 & Drugs & 0.784 & 0.239 \\
\hline Beer & 0.322 & 0.333 & Util & 0.525 & 0.236 \\
\hline Hlth & 0.611 & 0.323 & Hlth & 1.142 & 0.228 \\
\hline Oil & 0.754 & 0.305 & Hshld & 0.804 & 0.202 \\
\hline Food & 0.352 & 0.303 & Ships & 1.088 & 0.184 \\
\hline Insur & 0.878 & 0.283 & MedEq & 0.897 & 0.182 \\
\hline Soda & 0.573 & 0.254 & Insur & 0.964 & 0.161 \\
\hline Guns & 0.346 & 0.250 & Meals & 1.056 & 0.154 \\
\hline Aero & 0.972 & 0.249 & Guns & 0.818 & 0.126 \\
\hline RlEst & 1.203 & 0.226 & Whlsl & 1.043 & 0.121 \\
\hline Whlsl & 0.818 & 0.225 & Agric & 0.863 & 0.120 \\
\hline BldMt & 1.129 & 0.209 & Banks & 1.073 & 0.110 \\
\hline Txtls & 1.340 & 0.205 & PerSv & 1.103 & 0.100 \\
\hline Hshld & 0.477 & 0.185 & BldMt & 1.165 & 0.100 \\
\hline Chems & 1.080 & 0.177 & Gold & 0.641 & 0.098 \\
\hline Cnstr & 1.181 & 0.174 & Paper & 0.967 & 0.091 \\
\hline Banks & 0.981 & 0.170 & Mines & 1.103 & 0.082 \\
\hline Drugs & 0.497 & 0.170 & Aero & 1.134 & 0.077 \\
\hline Paper & 0.850 & 0.156 & Oil & 0.792 & 0.065 \\
\hline Meals & 0.670 & 0.155 & Rubbr & 1.063 & 0.064 \\
\hline FabPr & 1.158 & 0.146 & Chems & 1.037 & 0.063 \\
\hline PerSv & 0.769 & 0.144 & Clths & 1.129 & 0.055 \\
\hline MedEq & 0.663 & 0.121 & Boxes & 0.956 & 0.049 \\
\hline Trans & 0.889 & 0.113 & Toys & 1.167 & 0.046 \\
\hline Boxes & 1.032 & 0.100 & Other & 1.150 & 0.044 \\
\hline Agric & 0.701 & 0.090 & Txtls & 1.127 & 0.041 \\
\hline Other & 0.887 & 0.083 & RlEst & 1.196 & 0.032 \\
\hline Rubbr & 0.981 & 0.076 & Rtail & 1.005 & 0.023 \\
\hline Toys & 0.949 & 0.075 & Cnstr & 1.301 & 0.020 \\
\hline Clths & 1.017 & 0.051 & Books & 1.060 & 0.018 \\
\hline Books & 1.000 & 0.049 & Fun & 1.361 & 0.013 \\
\hline Fun & 1.507 & 0.045 & Trans & 1.067 & 0.005 \\
\hline ElcEq & 1.303 & 0.032 & FabPr & 1.091 & 0.001 \\
\hline Autos & 1.418 & 0.029 & ElcEq & 1.207 & -0.010 \\
\hline Mach & 1.410 & 0.020 & Telcm & 0.781 & -0.039 \\
\hline Steel & 1.810 & -0.012 & Mach & 1.227 & -0.074 \\
\hline Telcm & 1.001 & -0.046 & Autos & 1.133 & -0.096 \\
\hline Rtail & 0.813 & -0.082 & Steel & 1.295 & -0.138 \\
\hline Fin & 1.505 & -0.163 & Fin & 1.241 & -0.149 \\
\hline LabEq & 1.416 & -0.260 & LabEq & 1.333 & -0.167 \\
\hline BusSv & 1.341 & -0.290 & BusSv & 1.307 & -0.186 \\
\hline Comps & 1.604 & -0.339 & Comps & 1.235 & -0.261 \\
\hline Chips & 1.629 & -0.346 & Chips & 1.413 & -0.305 \\
\hline Mean & 0.974 & 0.152 & & 1.041 & 0.091 \\
\hline Std. & 0.383 & 0.248 & & 0.206 & 0.220 \\
\hline
\end{tabular}




\section{Panel B. Test Asset Boycott Factor Loadings for the FF25 Assets}

The boycott factor betas for each of the 25 size and value sorted assets (a subset of the FF55 assets) obtained in the context of the two-factor boycott-augmented CAPM are presented for the 1999-2012 and 1963-2012 periods.

\begin{tabular}{|l|rrrrr}
\multicolumn{7}{c}{$1999-2012$} & \multicolumn{1}{c}{ Size } \\
\hline BCT Beta & Smallest & \multicolumn{1}{c}{2} & 3 & 4 & Largest \\
\hline Lowest & -0.366 & -0.255 & -0.220 & -0.196 & -0.035 \\
$\stackrel{\Xi}{\rightleftharpoons}$ & -0.194 & -0.020 & 0.064 & 0.163 & 0.130 \\
3 & -0.116 & 0.070 & 0.182 & 0.217 & 0.161 \\
4 & -0.050 & 0.101 & 0.232 & 0.231 & 0.283 \\
Highest & 0.025 & 0.128 & 0.206 & 0.277 & 0.228
\end{tabular}

\begin{tabular}{|l|rrrrr}
\multicolumn{7}{c}{$1963-2012$} & \multicolumn{6}{c}{ Size } \\
\hline BCT Beta & Smallest & \multicolumn{1}{c}{2} & \multicolumn{1}{c}{3} & \multicolumn{1}{c}{4} & Largest \\
\hline \multirow{5}{*}{$\stackrel{\text { Lowest }}{\supset}$} & -0.257 & -0.165 & -0.140 & -0.107 & 0.047 \\
2 & -0.149 & -0.048 & -0.001 & 0.048 & 0.082 \\
3 & -0.089 & 0.006 & 0.046 & 0.081 & 0.049 \\
4 & -0.056 & 0.022 & 0.083 & 0.109 & 0.121 \\
Highest & -0.034 & 0.019 & 0.068 & 0.113 & 0.085
\end{tabular}




\section{Table 7 Excess Returns of Portfolios Sorted by (Narrow) Boycott Factor Loadings}

Panel A. After eliminating all stocks (NYSE/AMEX/NASDQ) that have any sin characteristics, the remaining stocks are sorted based on their boycott factor loadings. The boycott loadings are obtained by regressing the individual non-sin stock returns on the FF3 factors plus the narrowly defined boycott factor or on the FF4 factors plus the narrowly defined boycott factor for the period 1999-2012. All non-sin stocks are assigned to five portfolio based on these boycott factor loadings. Similarly, all sin stocks from the (narrow) boycott factor are assigned to five portfolios based on their boycott factor loadings. The numbers provided are boycott betas based on either the augmented FF3 or augmented FF4 model (BCT $\beta$ ) and the equal-weighted average monthly excess returns of each portfolio (FF3 or FF4).

\begin{tabular}{l|cc|cc|cc|cc}
\hline \hline \multirow{2}{*}{$\begin{array}{l}\text { BCT Loading } \\
\text { Ranked }\end{array}$} & \multicolumn{4}{|c|}{ Sin Stocks } & \multicolumn{4}{c}{ Non-Sin Stocks } \\
\cline { 2 - 9 } & BCT $\beta$ & FF3 & BCT $\beta$ & FF4 & BCT $\beta$ & FF3 & BCT $\beta$ & FF4 \\
\hline Average & 0.569 & 1.074 & 0.602 & 1.108 & -0.058 & 0.840 & -0.054 & 0.833 \\
\hline 1 (Least) & -0.676 & 0.904 & -0.585 & 1.132 & -1.042 & 0.515 & -1.041 & 0.405 \\
2 & 0.031 & 0.761 & 0.082 & 0.877 & -0.233 & 0.822 & -0.231 & 0.815 \\
3 & 0.300 & 0.998 & 0.302 & 0.827 & -0.007 & 0.949 & -0.006 & 0.994 \\
4 & 0.848 & 1.291 & 0.851 & 1.291 & 0.191 & 0.972 & 0.188 & 0.963 \\
5 (Most) & 2.341 & 1.415 & 2.361 & 1.415 & 0.800 & 0.943 & 0.819 & 0.986 \\
\hline $5-1$ & 3.017 & 0.511 & 2.946 & 0.283 & 1.842 & 0.428 & 1.860 & 0.581 \\
\hline
\end{tabular}

Panel B. The risk-adjusted return of a zero-investment strategy utilizing only non-sin stocks is obtained based on equation (18). The time-series regression result is reported. The dependent variable is the return on an equal-weighted portfolio that longs the most boycott-sensitive and shorts the least boycott-sensitive non-sin stocks.

\begin{tabular}{l|rr|rr}
\hline \hline & Estimate & t-stat & Estimate & t-stat \\
\hline Alpha & 0.445 & 1.626 & 0.420 & 1.596 \\
MKT & -0.169 & -2.825 & -0.056 & -0.900 \\
SMB & -0.272 & -3.390 & -0.271 & -3.463 \\
HML & 0.009 & 0.114 & 0.090 & 1.155 \\
UMD & & & 0.130 & 2.768 \\
\hline
\end{tabular}




\section{Table 8 Boycott Factor or Litigation Risk}

The table reports the factor risk premiums for the 1999-2012 time period estimated from cross-sectional regressions of the CAPM, Boycott-CAPM, FF3, Boycott-FF3, FF4, and Boycott-FF4 models for the FF30 and FF48 industry test portfolios, using the narrow Boycott factor measure, based on the tobacco, alcohol, and coal industries. The t-statistics use the Black-Jensen-Scholes cross-sectional regression slope standard errors. The adjusted R-square is from a single cross-sectional regression. The cross-sectional litigation ( $L T G)$ variable is constructed by scaling the number of lawsuits by each industry's market capitalization. The number of lawsuits is measured by counting the non-missing Settlement (Litigation/Insurance) AfterTax items in the Compustat North American Annual file.

\begin{tabular}{lcccccccc}
\hline \hline FF30 & Const & MKT & SMB & HML & UMD & BCT & LTG & $\mathrm{R}^{2}$ \\
\hline RP & -0.136 & 0.065 & & & & & 5.483 & 0.083 \\
$B J S-t$ & -0.379 & 0.139 & & & & & 2.053 & \\
& & & & & & & & \\
RP & -0.335 & 0.573 & & & & 1.291 & 0.704 & 0.463 \\
$B J S-t$ & -0.857 & 1.095 & & & & 2.135 & 0.321 & \\
& & & & & & & & \\
RP & 0.120 & -0.234 & 0.724 & 0.180 & & & 5.017 & 0.155 \\
$B J S-t$ & 0.358 & -0.458 & 1.385 & 0.546 & & & 1.895 & \\
RP & -0.243 & 0.519 & 0.052 & 0.192 & & 1.276 & 0.646 & 0.433 \\
$B J S-t$ & -0.646 & 0.974 & 0.115 & 0.584 & & 2.007 & 0.295 & \\
RP & -0.066 & 0.092 & 0.601 & 0.306 & 1.727 & & 4.123 & 0.486 \\
$B J S-t$ & -0.175 & 0.176 & 1.225 & 0.908 & 1.554 & & 1.723 & \\
& & & & & & & & \\
RP & -0.231 & 0.451 & 0.232 & 0.277 & 0.988 & 0.888 & 1.751 & 0.550 \\
$B J S-t$ & -0.622 & 0.882 & 0.483 & 0.814 & 0.912 & 1.724 & 0.761 & \\
\hline
\end{tabular}

\begin{tabular}{lllllllll}
\hline \hline FF48 & Const & MKT & SMB & HML & UMD & BCT & LTG & $\mathrm{R}^{2}$ \\
\hline RP & -0.006 & 0.087 & & & & & 4.297 & 0.096 \\
$B J S-t$ & -0.019 & 0.192 & & & & & 2.030 & \\
& & & & & & & & \\
RP & -0.298 & 0.470 & & & & 1.358 & 1.967 & 0.412 \\
$B J S-t$ & -0.878 & 1.004 & & & & 2.272 & 1.016 & \\
& & & & & & & & \\
RP & -0.010 & 0.059 & 0.225 & 0.150 & & & 3.765 & 0.117 \\
$B J S-t$ & -0.032 & 0.133 & 0.602 & 0.457 & & & 1.918 & \\
& & & & & & & & \\
RP & -0.213 & 0.399 & 0.135 & 0.143 & & 1.169 & 2.001 & 0.426 \\
$B J S-t$ & -0.653 & 0.875 & 0.367 & 0.433 & & 2.076 & 1.040 & \\
& & & & & & & & \\
RP & -0.167 & 0.304 & 0.291 & 0.241 & 1.420 & & 3.342 & 0.417 \\
$B J S-t$ & -0.499 & 0.657 & 0.760 & 0.730 & 1.451 & & 1.741 & \\
& & & & & & & & \\
RP & -0.260 & 0.466 & 0.207 & 0.207 & 0.875 & 0.925 & 2.239 & 0.536 \\
$B J S-t$ & -0.769 & 0.989 & 0.548 & 0.624 & 0.962 & 1.906 & 1.168 & \\
\hline
\end{tabular}




\section{Table 9 Boycott Factor or Idiosyncratic Liquidity}

The table reports the factor risk premiums estimated from cross-sectional regressions of the CAPM, Boycott-CAPM, FF3, Boycott-FF3, FF4, and Boycott-FF4 models for FF30 and FF48 industry test portfolios, using the narrow Boycott factor measure, based on the tobacco, alcohol, and coal industries. The t-statistics use the Black-Jensen-Scholes cross-sectional regression slope standard errors. The adjusted R-square is from a single cross-section regression. The cross-sectional idiosyncratic liquidity measure (ILQ) is the average Amihuid (2002) market-adjusted illiquidity across all firms within individual FF30 and FF48 industries.

\begin{tabular}{lcccccccc}
\hline \hline FF30 & Const & MKT & SMB & HML & UMD & BCT & ILQ & $\mathrm{R}^{2}$ \\
\hline RP & 0.660 & 0.102 & & & & & -0.306 & 0.024 \\
$B J S-t$ & 1.898 & 0.218 & & & & & -1.184 & \\
& & & & & & & & \\
RP & -0.195 & 0.575 & & & & 1.288 & -0.084 & 0.467 \\
$B J S-t$ & -0.590 & 1.140 & & & & 2.291 & -0.360 & \\
& & & & & & & & \\
RP & 0.733 & -0.073 & 0.506 & 0.355 & & & -0.372 & 0.151 \\
$B J S-t$ & 1.882 & -0.145 & 1.060 & 1.051 & & & -1.425 & \\
RP & -0.185 & 0.545 & 0.026 & 0.207 & & 1.308 & -0.027 & 0.432 \\
$B J S-t$ & -0.640 & 1.096 & 0.057 & 0.613 & & 2.360 & -0.144 & \\
RP & 0.363 & 0.164 & 0.534 & 0.382 & 1.613 & & -0.106 & 0.404 \\
$B J S-t$ & 0.984 & 0.316 & 1.105 & 1.119 & 1.490 & & -0.586 & \\
& & & & & & & & \\
RP & -0.224 & 0.563 & 0.163 & 0.263 & 0.906 & 1.088 & 0.079 & 0.542 \\
$B J S-t$ & -0.741 & 1.120 & 0.349 & 0.758 & 0.873 & 2.224 & 0.485 & \\
\hline
\end{tabular}

\begin{tabular}{lcccccccc}
\hline \hline FF48 & Const & MKT & SMB & HML & UMD & BCT & ILQ & $\mathrm{R}^{2}$ \\
\hline RP & 0.627 & 0.098 & & & & & -0.216 & 0.033 \\
$B J S-t$ & 1.962 & 0.217 & & & & & -1.258 & \\
& & & & & & & & \\
RP & -0.255 & 0.559 & & & & 1.358 & -0.025 & 0.439 \\
$B J S-t$ & -0.735 & 1.080 & & & & 2.483 & -0.103 & \\
& & & & & & & & \\
RP & 0.515 & 0.126 & 0.231 & 0.287 & & & -0.291 & 0.142 \\
$B J S-t$ & 1.733 & 0.284 & 0.616 & 0.867 & & & -1.717 & \\
RP & 0.041 & 0.419 & 0.137 & 0.201 & & 1.192 & -0.098 & 0.410 \\
$B J S-t$ & 0.145 & 0.920 & 0.369 & 0.602 & & 2.232 & -0.710 & \\
RP & 0.264 & 0.322 & 0.288 & 0.330 & 1.265 & & -0.155 & 0.367 \\
$B J S-t$ & 0.908 & 0.694 & 0.752 & 0.988 & 1.337 & & -1.182 & \\
& & & & & & & & \\
RP & -0.024 & 0.488 & 0.199 & 0.251 & 0.791 & 1.013 & -0.047 & 0.503 \\
$B J S-t$ & -0.081 & 1.038 & 0.522 & 0.744 & 0.878 & 2.105 & -0.373 & \\
\hline
\end{tabular}




\section{Table 10 Boycott Factor or Systematic Liquidity Risk}

The table reports the factor risk premiums estimated from cross-sectional regressions of the CAPM, Boycott-CAPM, FF3, Boycott-FF3, FF4, and Boycott-FF4 models for FF30 and FF48 industry test portfolios, using the narrow Boycott factor measure, based on the tobacco, alcohol, and coal industries. The t-statistics use the Black-Jensen-Scholes cross-sectional regression slope standard errors. The adjusted R-square is from a single cross-section regression. The cross-sectional systematic liquidity measures $(S L Q)$ are the test portfolios' sensitivities to the monthly Pastor-Stambaugh Traded Liquidity Factor.

\begin{tabular}{lcccccccc}
\hline \hline FF30 & Alpha & MKT & SMB & HML & UMD & BCT & SLQ & $\mathrm{R}^{2}$ \\
\hline RP & 0.563 & -0.156 & & & & & 1.453 & 0.560 \\
$B J S-t$ & 1.757 & -0.333 & & & & & 1.933 & \\
& & & & & & & & \\
RP & 0.050 & 0.239 & & & & 0.957 & 1.146 & 0.759 \\
$B J S-t$ & 0.172 & 0.510 & & & & 1.959 & 1.612 & \\
RP & 0.655 & -0.312 & 0.454 & 0.074 & & & 1.350 & 0.588 \\
$B J S-t$ & 1.817 & -0.608 & 0.964 & 0.222 & & & 1.814 & \\
RP & 0.106 & 0.205 & 0.050 & 0.084 & & 0.947 & 1.146 & 0.745 \\
$B J S-t$ & 0.347 & 0.430 & 0.111 & 0.253 & & 1.859 & 1.611 & \\
RP & 0.568 & -0.200 & 0.462 & 0.133 & 0.740 & & 1.144 & 0.584 \\
$B J S-t$ & 1.712 & -0.408 & 0.974 & 0.410 & 0.787 & & 1.837 & \\
& & & & & & & & \\
RP & 0.117 & 0.183 & 0.032 & 0.062 & -0.174 & 0.966 & 1.216 & 0.736 \\
$B J S-t$ & 0.374 & 0.376 & 0.070 & 0.190 & -0.209 & 1.948 & 1.947 & \\
\hline
\end{tabular}

\begin{tabular}{lcccccccc}
\hline \hline FF48 & Alpha & MKT & SMB & HML & UMD & BCT & SLQ & $\mathrm{R}^{2}$ \\
\hline RP & 0.572 & -0.119 & & & & & 1.314 & 0.444 \\
$B J S-t$ & 1.790 & -0.261 & & & & & 1.902 & \\
& & & & & & & & \\
RP & 0.111 & 0.237 & & & & 0.942 & 1.064 & 0.638 \\
$B J S-t$ & 0.443 & 0.532 & & & & 1.856 & 1.598 & \\
& & & & & & & & \\
RP & 0.456 & -0.09 & 0.139 & 0.117 & & & 1.260 & 0.480 \\
$B J S-t$ & 1.662 & -0.200 & 0.379 & 0.351 & & & 1.830 & \\
& & & & & & & & \\
RP & 0.154 & 0.197 & 0.094 & 0.113 & & 0.952 & 1.039 & 0.632 \\
$B J S-t$ & 0.615 & 0.451 & 0.257 & 0.339 & & 2.023 & 1.590 & \\
& & & & & & & & \\
RP & 0.352 & 0.049 & 0.186 & 0.174 & 0.701 & & 1.000 & 0.502 \\
$B J S-t$ & 1.374 & 0.111 & 0.499 & 0.531 & 0.817 & & 1.652 & \\
& & & & & & & & \\
RP & 0.126 & 0.240 & 0.117 & 0.138 & 0.245 & 0.924 & 0.940 & 0.629 \\
$B J S-t$ & 0.503 & 0.549 & 0.314 & 0.416 & 0.296 & 2.004 & 1.567 & \\
\hline
\end{tabular}




\section{Table 11 Boycott Factor or Neglect Effect}

The table reports the factor risk premiums for the 1999-2012 period estimated from cross-sectional regressions of the CAPM, Boycott-CAPM, FF3, Boycott-FF3, FF4, and Boycott-FF4 models for FF30 and FF48 industry test portfolios, using the narrow Boycott factor measure, based on the tobacco, alcohol, and coal industries. The t-statistics use the Black-Jensen-Scholes cross-sectional regression slope standard errors. The adjusted R-square is from a single cross-section regression. The cross-sectional neglect (NGL) measure is constructed by taking the log of the number of analysts following an industry scaled by the $\log$ of each industry's market capitalization.

\begin{tabular}{lcccccccc}
\hline \hline FF30 & Const & MKT & SMB & HML & UMD & BCT & NGL & $\mathrm{R}^{2}$ \\
\hline RP & 2.083 & 0.142 & & & & & -0.177 & 0.153 \\
$B J S-t$ & 2.121 & 0.302 & & & & & -1.992 & \\
& & & & & & & & \\
RP & -0.439 & 0.607 & & & & 1.375 & 0.014 & 0.462 \\
$B J S-t$ & -0.482 & 1.180 & & & & 2.184 & 0.195 & \\
RP & 1.842 & -0.055 & 0.464 & 0.067 & & & -0.136 & 0.118 \\
$B J S-t$ & 2.078 & -0.111 & 0.956 & 0.199 & & & -1.818 & \\
RP & -0.258 & 0.553 & 0.030 & 0.203 & & 1.338 & 0.004 & 0.432 \\
$B J S-t$ & -0.357 & 1.069 & 0.066 & 0.623 & & 2.120 & 0.077 & \\
RP & 1.309 & 0.239 & 0.393 & 0.219 & 1.625 & & -0.108 & 0.456 \\
$B J S-t$ & 1.741 & 0.459 & 0.832 & 0.652 & 1.499 & & -1.644 & \\
& & & & & & & & \\
RP & 0.141 & 0.533 & 0.139 & 0.257 & 0.889 & 0.971 & -0.027 & 0.541 \\
$B J S-t$ & 0.206 & 1.044 & 0.298 & 0.775 & 0.842 & 1.874 & -0.436 & \\
\hline
\end{tabular}

\begin{tabular}{lcccccccc}
\hline \hline FF48 & Const & MKT & SMB & HML & UMD & BCT & NGL & $\mathrm{R}^{2}$ \\
\hline RP & 1.525 & 0.107 & & & & & -0.128 & 0.091 \\
$B J S-t$ & 2.115 & 0.236 & & & & & -1.880 & \\
& & & & & & & & \\
RP & -0.124 & 0.549 & & & & 1.347 & -0.016 & 0.441 \\
$B J S-t$ & -0.171 & 1.022 & & & & 2.191 & -0.288 & \\
RP & 1.264 & 0.166 & -0.010 & 0.159 & & & -0.112 & 0.085 \\
$B J S-t$ & 2.149 & 0.371 & -0.026 & 0.482 & & & -1.892 & \\
RP & 0.427 & 0.461 & 0.015 & 0.148 & & 1.222 & -0.056 & 0.415 \\
$B J S-t$ & 0.757 & 1.007 & 0.039 & 0.449 & & 2.200 & -0.999 & \\
& & & & & & & & \\
RP & 0.971 & 0.403 & 0.081 & 0.249 & 1.319 & & -0.100 & 0.393 \\
$B J S-t$ & 1.776 & 0.860 & 0.207 & 0.755 & 1.369 & & -1.767 & \\
RP & 0.473 & 0.535 & 0.069 & 0.212 & 0.790 & 0.984 & -0.064 & 0.524 \\
$B J S-t$ & 0.839 & 1.129 & 0.177 & 0.639 & 0.873 & 2.039 & -1.128 & \\
\hline
\end{tabular}




\section{Table 12 Model Comparison for the Broad Boycott Factor}

The table reports the factor risk premiums for the 1999-2012 period estimated from cross-sectional regressions of the Boycott-CAPM, Boycott-FF3, Boycott-FF4 models for FF30 and FF48 industry test portfolios and FF55 (FF25+FF30), using the broad boycott factor measure, based on the tobacco, alcohol, fossil fuel, weapons, and gaming industries. The t-statistics are based on the Black-Jensen-Scholes cross-sectional regression slopes and the GMM t-statistics (with 12 monthly lags). The adjusted R-square is from a single cross-section regression.

\begin{tabular}{lccccccr}
\hline FF30 & Const & MKT & SMB & HML & UMD & BCT & $\mathrm{R}^{2}$ \\
\hline RP & 0.119 & 0.161 & & & & 1.080 & 0.682 \\
$B J S-t$ & 0.364 & 0.341 & & & & 2.162 & \\
$G M M-t$ & 0.284 & 0.295 & & & & 1.993 & \\
& & & & & & & \\
RP & 0.283 & 0.05 & 0.085 & 0.110 & & 1.056 & 0.694 \\
$B J S-t$ & 0.833 & 0.101 & 0.187 & 0.330 & & 2.080 & \\
$G M M-t$ & 0.754 & 0.090 & 0.259 & 0.303 & & 1.955 & \\
& & & & & & & \\
& & & & & & & \\
RP & 0.313 & -0.012 & -0.008 & 0.042 & -0.413 & 1.174 & 0.695 \\
$B J S-t$ & 0.878 & -0.024 & -0.018 & 0.123 & -0.455 & 2.515 & \\
$G M M-t$ & 0.746 & -0.019 & -0.022 & 0.126 & -0.435 & 2.204 & \\
\hline
\end{tabular}

\begin{tabular}{lccccccc}
\hline FF48 & Const & MKT & SMB & HML & UMD & BCT & $\mathrm{R}^{2}$ \\
\hline RP & 0.102 & 0.213 & & & & 1.066 & 0.644 \\
$B J S-t$ & 0.336 & 0.470 & & & & 2.211 & \\
$G M M-t$ & 0.254 & 0.395 & & & & 1.996 & \\
& & & & & & & \\
& & & & & & & \\
RP & 0.209 & 0.155 & -0.045 & 0.116 & & 1.113 & 0.675 \\
$B J S-t$ & 0.782 & 0.348 & -0.123 & 0.349 & & 2.236 & \\
$G M M-t$ & 0.647 & 0.287 & -0.169 & 0.305 & & 2.049 & \\
& & & & & & & \\
RP & 0.236 & 0.108 & -0.096 & 0.084 & -0.309 & 1.190 & 0.675 \\
$B J S-t$ & 0.856 & 0.237 & -0.26 & 0.248 & -0.374 & 2.492 & \\
$G M M-t$ & 0.664 & 0.189 & -0.34 & 0.226 & -0.407 & 2.210 & \\
\hline
\end{tabular}

\begin{tabular}{llllllll}
\hline FF55 & Const & MKT & SMB & HML & UMD & BCT & $\mathrm{R}^{2}$ \\
\hline RP & 0.126 & 0.296 & & & & 0.864 & 0.396 \\
$B J S-t$ & 0.377 & 0.600 & & & & 1.808 & \\
GMM- $t$ & 0.302 & 0.523 & & & & 1.692 & \\
& & & & & & & \\
& & & & & & & \\
RP & 0.437 & -0.134 & 0.416 & 0.198 & & 1.013 & 0.672 \\
$B J S-t$ & 1.500 & -0.285 & 1.4 & 0.657 & & 2.075 & \\
$G M M-t$ & 1.393 & -0.255 & 1.747 & 0.590 & & 1.998 & \\
& & & & & & & \\
& & & & & & & \\
RP & 0.414 & -0.101 & 0.412 & 0.210 & 0.427 & 0.986 & 0.666 \\
$B J S-t$ & 1.287 & -0.204 & 1.391 & 0.709 & 0.560 & 2.136 & \\
$G M M-t$ & 1.054 & -0.167 & 1.787 & 0.674 & 0.540 & 1.992 & \\
\hline
\end{tabular}




\section{Figure 1}
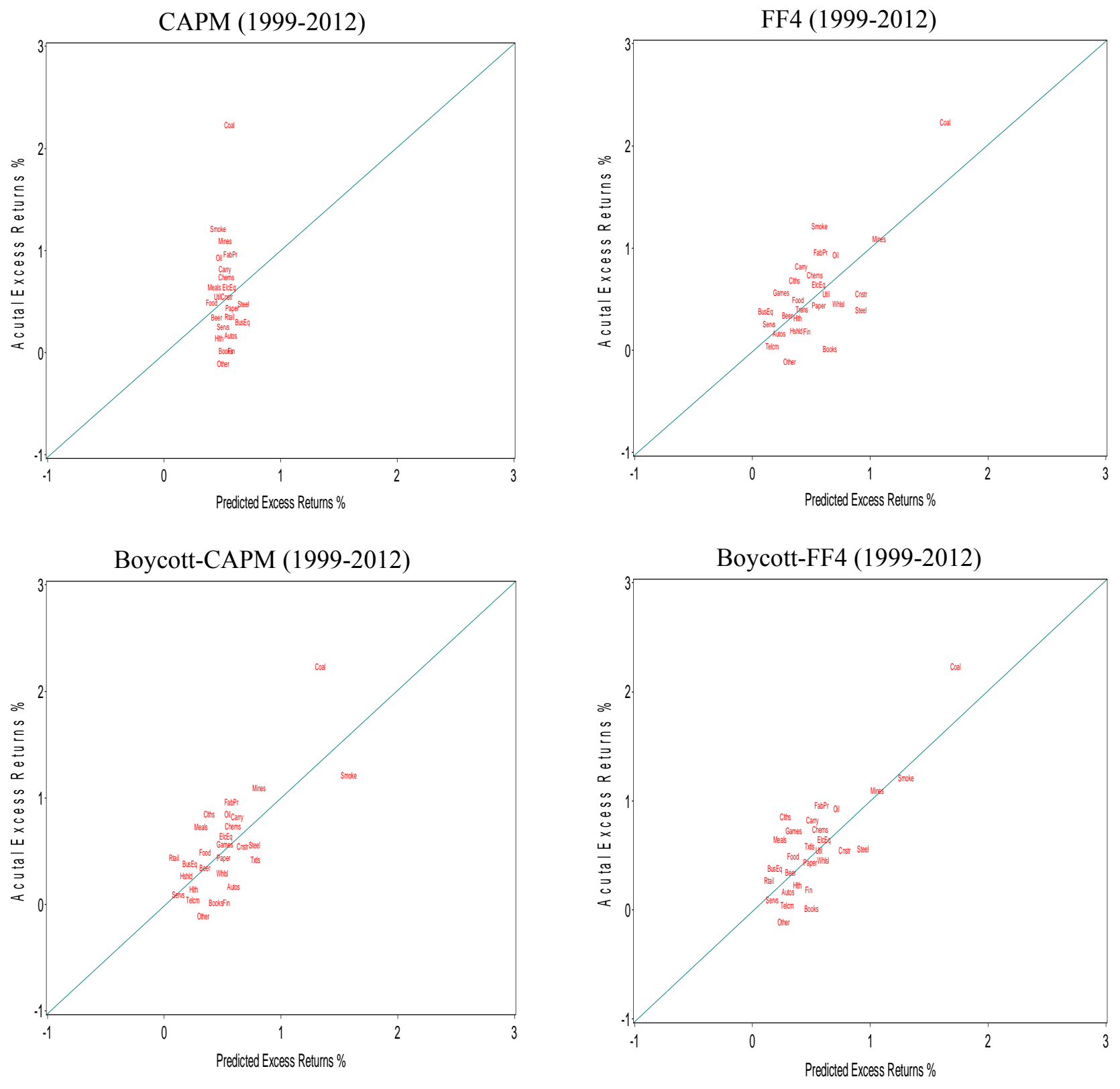
Figure 2
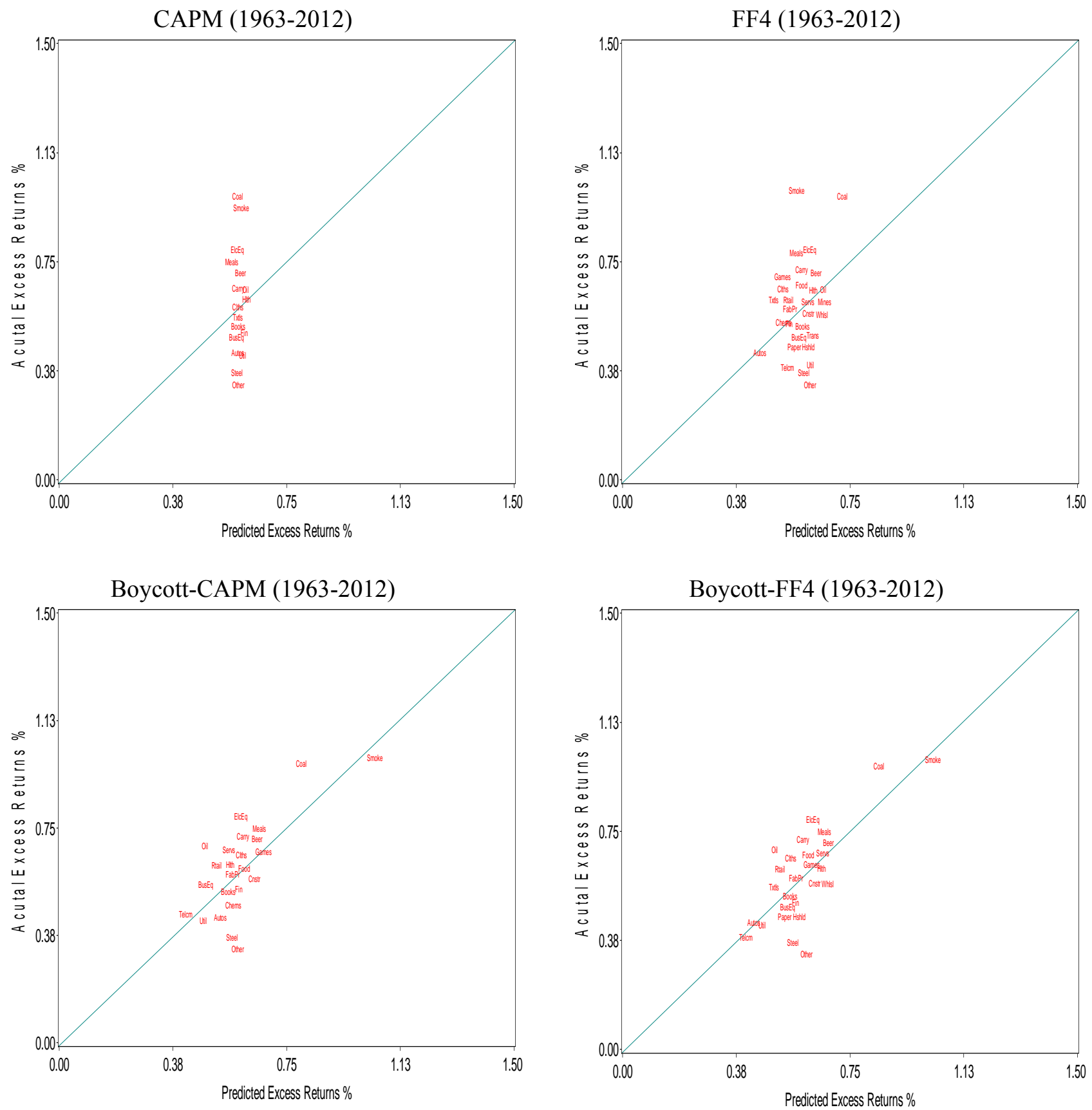